\title{
Understanding the Impact of Monetary Policy Shocks on the Corporate Bond Market in Good and Bad Times: A Markov Switching Model ${ }^{*}$
}

\author{
Massimo Guidolin \\ Bocconi University, IGIER
}

\author{
Alexei G. Orlov \\ Radford University
}

Manuela Pedio

Bocconi University

January 2014

\begin{abstract}
We study the effects of a conventional monetary expansion, quantitative easing, and operation twist on corporate bond yields and spreads. These policies are simulated as shocks to the Treasury yield curve, and the impulse response functions of corporate yields and spreads to shocks are computed using flexible models with regimes. We construct weekly bond portfolios sorting individual bond trades by rating and maturity using TRACE. The paper examines two types of models-single-state vector autoregressive (VAR) models and three-state Markov switching VAR models. Our results indicate that a standard single-state VAR model is inadequate to capture the dynamics of the data. We find that none of the policies-conventional or unconventional-can persistently lower corporate spreads. This result is likely due to the negative expectations about the business cycle generated by these policies, which affect bond risk premia. Operation twist is the only policy capable of lowering corporate yields. This finding can be explained by the fact that operation twist, which does not imply an expansion of the monetary base, is able to flatten the riskless yield curve without generating expectations of higher future inflation.
\end{abstract}

Keywords: Unconventional monetary policy, corporate bonds, term structure of Treasury yields, vector autoregression, Markov switching.

JEL codes: G12, E43, C32.

\footnotetext{
${ }^{*}$ We thank William Maxwell for sharing with us his SAS code that provided a starting point for TRACE elaborations.
} 


\section{Introduction}

The financial crisis has offered unprecedented challenges to policymakers worldwide (see, e.g., Joyce et al., 2012). In the U.S., the Federal Reserve was forced to reduce its target federal funds rate to zero and to massively increase the monetary base in an attempt to stabilize the financial system and stimulate the economy. ${ }^{1}$ In November 2008, the FOMC started a Large-Scale Asset Purchases (LSAP) program, consisting of purchases of large amounts of long-term assets, mainly agency bonds and agency (Fannie Mae, Freddie Mac, and the Federal Home Loan Bank, issuers of securities that are backed, but not guaranteed, by the U.S. government) MBS securities, initially up to $\$ 600$ billion. In March 2009, the purchases were expanded to long-term Treasury securities up to additional $\$ 600$ billion. These policies, which imply the expansion of the high-powered monetary base (i.e., bank reserves and currency) through the direct purchase of longterm securities, are generally known as quantitative easing (QE) (see, e.g., Bowdler and Radia, 2012; Goodfriend, 2011). In addition, in September 2011 the FOMC launched the Maturity Extension Program (MEP), which consisted of purchases of $\$ 400$ billion worth of long-term Treasury securities and contemporaneous sales of the identical amount of short-term notes. In contrast to QE, the MEP, also commonly known as operation "twist" (OT), keeps the monetary base constant, as the proceeds from the sales of short-term Treasuries are used to buy long-term ones. ${ }^{2}$

The purpose of these unconventional policies, as stated in the minutes of the FOMC meeting of December 16, 2008, was to “(...) support overall market functioning, financial intermediation and economic growth." In addition, the minutes suggest that the asset purchases were expected not only to reduce the yields on the instruments being purchased, but also to "reduce borrowing costs for a range of private borrowers", such as the yields of corporate notes and bonds-i.e., those debt instruments that are issued by firms to satisfy their financing needs (see, e.g., Vayanos and Vila, 2009, for theoretical arguments based on the "preferred habitat" theory). In light of the objectives stated in the FOMC minutes, as well as considering the importance of debt financing for U.S. firms, it is particularly important to understand the effects of monetary policies on the corporate bond market. A focus on the U.S. corporate fixed income market is easily justified: corporate bonds represent a significant source of external financing for public companies,

\footnotetext{
${ }^{1}$ By the end of 2008, the Federal Open Market Committee (FOMC) had lowered the target federal funds rate, the traditional monetary policy instrument, to a range of 0 to 25 basis points (bps). As the target interest rate could not be lowered any further, the Fed had to resort to alternative, unconventional policies.

2 The original "operation twist" was introduced under the Kennedy administration to stimulate the economy during the recession of the early 1960s.
} 
which substantially exceeds equity financing for many firms. During the ten-year period from 2001 to 2010 , for example, U.S. corporate bond issuances amounted to $\$ 8.6$ trillion, compared to only $\$ 583$ billion in equity issuances. Accordingly, the goal of this paper is to investigate the effects that conventional and unconventional monetary policies may have been expected to produce on the yields and spreads of corporate bonds with different maturities and ratings.

In particular, our research design addresses three questions. First, we ask whether monetary policy shocks are transmitted to corporate bond markets. Here we distinguish between conventional shocks, based on changes in short-term (federal funds and T-bill) rates, and unconventional shocks. Although the latter affect the size and/or composition of the Fed balance sheet, they also end up affecting either long-term Treasury rates or the entire term structure of government yields. Second, we examine whether such shocks affect corporate yields through a change (of homogeneous sign) in credit risk premia or instead whether corporate rates and premia may move in opposite directions. Third, because QE and OT have different effects on the size of the central bank's balance sheet (only the former impacting on its size and the latter merely influencing its composition in terms of durations), we test whether these have a different impact on corporate yields and spreads because of their heterogeneous effects on inflation expectations.

The existing literature has investigated the effects of unconventional monetary policies on the securities that were directly purchased by the Fed, as well as the assets that were not purchased directly, such as MBS and corporate bonds. This strand of research includes D’Amico and King (2013), Gagnon et al. (2011), Greenwood and Vayanos (2013), Hamilton and $\mathrm{Wu}$ (2010), Krishnamurthy and Vissing-Jorgensen (2011), and Wright (2012). Our approach differs from these studies in that we do not propose an ex-post assessment, usually based on event studies, of unconventional monetary policies limited to the financial crisis period (see Martin and Milas, 2012), but rather an a-priori, fullsample investigation of the effects that these policies could be expected to produce at the time of implementation. Our analysis therefore uses longer time series drawn from a 2004-2012 sample that includes the financial crisis but it is not limited to it. However, exactly because two of the three types of policies investigated are unconventional, they have been rarely used, so any unconditional historical evidence would be by necessity unreliable. Hence we opt to use modern, flexible dynamic time series models that allow for instabilities in the mechanism linking the riskless yield curve to the U.S. corporate bond market. ${ }^{3}$ Moreover, whilst the event-study approach has difficulties pinning down

\footnotetext{
${ }^{3}$ In a related paper, Cronin (2013) has used (generalized, invariant to variable orderings) VAR variance decomposition methods to measure spillovers from both monetary base and M2 to the
} 
the persistence of the effects on corporate bond markets, our impulse-response functions are instead explicitly geared towards measuring such persistence properties. ${ }^{4}$

Specifically, our goal is to compare the effects of three types of policies: a conventional monetary expansion, quantitative easing, and operation twist. To this end, we employ two types of models: single-state vector autoregressive (VAR) models and three-state Markov switching (MS) models. MS models have recently become popular in the literature (see, e.g., Guidolin, 2012; Kapetanios et al., 2012), which can be attributed to the fact that financial time series are typically characterized by instability. For example, fixed income markets alternate low-rate and high-rate periods and also the volatility of innovations to interest rates tend to follow a regime-like pattern (see, e.g., Bansal and Zhou, 2002; Guidolin and Timmermann, 2009). Williams (2012) considers the implications of monetary policy under two distinct Markov regimes and points out that the optimal policy during the crisis state can be rather different from the optimal policy during tranquil periods. We therefore use both single-state VARs and multi-regime MS models to compute the impulse response functions (IRFs), which measure the effects of shocks to one or more policy variables on each of the series in the system. ${ }^{5}$

The choice of how to simulate the three policies in a dynamic time series model for Treasury and corporate yields (spreads) remains non-trivial. A conventional monetary expansion, which implies the injection of newly-created reserves into the system through the purchase of short-term Treasuries, is typically measured by changes in monetary aggregates. However, Bernanke and Mihov (1998) argue that this traditional approach fails to recognize that, in practice, the rate of growth of monetary aggregates depends also on a variety of non-policy factors. As an alternative, they suggest to use VAR innovations to the federal funds rate to identify conventional monetary policy shocks. Whereas the use of changes in monetary aggregates as a measure of conventional monetary policies is questionable, this approach is impractical to simulate unconventional monetary policies

returns on four asset classes (stocks, commodities, currency index, and government bonds). QE measures are identified as shocks to the rate of growth of monetary aggregates. In our paper, we go beyond single-state VAR methodologies to accommodate the presence of regimes, and focus on a key link of the transmission mechanism - the corporate bond market.

${ }^{4}$ Bekaert et al. (2013) use a VAR framework to study another important implication of monetary policy for financial markets-namely, the effects of the Fed's actions on risk preferences and on the expected variance of stock returns. Decomposing the option-based implied volatility index (VIX) into a pure volatility component (which proxies for uncertainty) and a residual (which proxies for risk aversion), Bekaert et al. find that an expansionary monetary policy persistently decreases both risk aversion (albeit with a lag) and expected volatility. They also point to the feedback effects from risk aversion and uncertainty to the stance of monetary policy.

${ }^{5}$ Because we focus on reduced-form impacts, we do not identify how the policies are transmitted to the economy, through either portfolio balance or/and inflation expectations or other channels. 
and, in particular, operation twist because this policy does not imply the creation of monetary base but a change in the relative supply of long- and short-term Treasuries obtained through a change in the composition of the balance sheet of the Federal Reserve. For these reasons we simulate monetary policy shocks through their effects on Treasury rates. This approach is sensible because the vast majority of monetary policy operations, both conventional and unconventional, are carried out with purchases or sales of Treasuries. Additionally, many studies have demonstrated that such purchases and sales do affect Treasury yields (e.g., see Table 1 in Chen et al., 2012, and references therein). ${ }^{6}$

We use the 1-month T-bill yield to represent short-term Treasury rates and the 10-year note yield to represent long-term rates. Accordingly, a conventional monetary expansion, which implies a shock to the short end of the yield curve, is simulated as a negative shock to the 1-month yield. QE, which is implemented through the purchase of long-term securities (as emphasized by Bowdler and Radia, 2012, this occurs because these are less close substitutes for money so that changes in relative holdings of money vs. long-term Treasuries may induce portfolio rebalancing and movements in asset prices), is simulated as a negative shock to the 10-year yield, similarly to Kapetanios et al. (2012). Finally, OT, which involves the sale of short-term Treasury notes and the contemporaneous purchase of longer-term Treasuries, is simulated as a negative shock to the 10-year Treasury yield accompanied by a simultaneous positive shock to the 1-month yield. Because it can be argued that the choice of 1-month and 10-year government note yields to represent short and long-term rates is somewhat arbitrary, we also propose a set robustness checks of our results. In particular, we repeat our analysis using the principal components method suggested by Littermann and Scheinkman (1991) that allows us to decompose the Treasury yield curve into three factors-namely, level, slope, and curvature. A conventional monetary policy is then simulated through a negative shock to the level factor, and OT through a negative shock to the slope factor. Although it is more difficult to understand how to simulate $\mathrm{QE}$ in this context, we approximate this policy by contemporaneous negative shocks to both level and slope.

We propose a set of four empirical experiments. First, we estimate a single-state VAR model which includes four series of weekly corporate yields (investment grade short- and long-term and non-investment-grade short- and long-term) and four series of weekly Treasury yields (1-month, 1-, 5-, and 10-year Treasury). Second, we conduct a similar exercise for spreads. Third, we estimate a three-state Markov switching VAR model for

${ }^{6}$ This approach excludes from our investigation the effects of the purchases of MBS and agency bonds, what is often referred to as "credit easing". While many studies conclude that MBS purchases were quite effective in achieving the goals of the monetary authorities (e.g., Gagnon et al., 2010), the effects of Treasury purchases on other risky bonds remain by far less clear. 
yields or spreads. Finally, to test the robustness of results, we repeat the exercises replacing the Treasury yields with level, slope, and curvature factors. As far as corporate yields and spreads are concerned, we emphasize our use of own-computed portfolios of corporate bonds instead of relying on indices, such as those produced by Moody's or Barclays' ${ }^{7}$ To compute yield and spread series we rely on raw data from the Trade Reporting and Compliance Engine (TRACE), maintained by the Financial Industry Regulatory Authority (FINRA).

Our analysis leads to two main empirical findings. First, a traditional, single-state VAR approach is insufficient to model corporate bonds rates. In fact, it fails to recognize that the magnitude and, occasionally, the sign of the responses of corporate yields and spreads to policy shocks depend on the underlying macroeconomic conditions. Since a MS model allows for regime shifts, it is able to detect and capture the instability in the data. In particular, we recognize the presence of a low rates/high spreads regime, a high rates/low spreads regime, and a crisis regime. Second, our results show that in the crisis regime, OT is the only policy that leads to a general and persistent decline in corporate yields. As discussed above, this is in line with the objectives of the monetary authorities and it implies a reduction of the borrowing costs for bond issuers. In contrast, conventional monetary expansion and QE policies tend to produce an increase in corporate yields and lead to higher borrowing costs perceived by firms, which may cause perverse effects on the level of real investments and, ultimately, on employment. Although clearly puzzling, this result is not completely surprising, especially if we consider that the policies under investigation imply an expansion of the monetary base, which is likely to produce an increase in inflation, as suggested by Bernanke and Mihov (1998). In turn, expected inflation has been found to produce an increase in corporate yields through the adjustment of investors' expectations, as showed by Ang and Piazzesi (2003). In contrast, OT holds the monetary base fixed, thereby circumventing the problems related to inflationary expectations, hence its higher effectiveness (in line with typical policymakers' goals) (see Joyce et al., 2012). ${ }^{8}$

To the best of our knowledge, the empirical findings and regime switching approach employed in our paper are new. However, a few earlier papers have obtained related results, mostly using event-study methods. For instance, Krishnamurthy and Vissing-

\footnotetext{
7 This aspect is important because corporate bond indices are usually constructed using both callable and non-callable bonds. The call option embedded in callable bonds impacts the price, and thus the yield, of the bond.

${ }^{8}$ Even in the crisis regime, monetary policies are likely to be interpreted as a signal of concern of the monetary authorities for the economic outlook. Given this perception, bond risk premia, and thus credit spreads, may increase, for instance following the channel in Gourio (2013).
} 
Jorgensen (2011) emphasize that LSAP produced a significant drop in the rates of longterm safe assets and it barely affected risky assets such as Baa corporate bonds. Our findings show that some policies (OT) may instead cause important and statistically significant effects, but in the crisis regime only. Wright (2012) has used a structural VAR to identify the effects of unconventional monetary policy on various long-term interest rates. He concludes that LSAP1 and LSAP2 had statistically significant effects on longterm Treasury as well as corporate yields, but these effects tended to reverse in subsequent months. Swanson (2011) investigates the implications of OT using a highfrequency event study and concludes that this policy had smaller effects than LSAP: it lowered long-term Treasury yields by 15 bps while barely affecting the corporate yields. Our empirical views on the effectiveness of OT are considerably more benign, even though these implications are derived from a multi-state model and with reference to some regimes only. More generally, the existing literature on unconventional policies suggests that, while there is a general consensus regarding the LSAP's and the OT's success in lowering long-term Treasury rates and the yields of the other assets being purchased, there is less evidence of their ability to lower the interest rates paid by the private sector (see Martin and Milas, 2012). This is exactly the question of our paper. ${ }^{9}$

There is also a small literature on the relationship between credit spreads and the Treasury term structure. Although most of the studies document a negative short-term relationship between credit spreads and the level of Treasury yields, there is much less agreement on the long-term relationship. In addition, the evidence concerning the relation between credit spreads and the slope of the Treasury yield curve is mixed. For instance, Duffee (1998) studies the effects of the changes of the Treasury yield curve on corporate spreads. He regresses the changes in spreads of non-callable corporate bonds on the changes in level (the three-month T-bill rate) and slope (the difference between the 30-year constant-maturity Treasury yield and the three-month T-bill) of the riskless yield curve. In addition, he uses VARs and impulse response functions to investigate the persistence of the changes in spreads associated with a change in Treasury rates. Duffee's results indicate that a decrease in the three-month yield produces a general increase in corporate spreads, which is more pronounced for non-investment grade bonds. Further, his data support a negative relation between corporate spreads and the slope of the Treasury yield curve, particularly for longer-term bonds. Neal et al. (2000) use

\footnotetext{
${ }_{9}^{9}$ Joyce et al. $(2011,2012)$ give a positive assessment in the case of the UK: "Corporate bond yields did decline substantially in the months after the start of the Bank's asset purchase programmes, particularly in 2009 when most of the purchases were made (...)" (p. F279). However, they add that "How much of that decline was due to asset purchases by central banks is impossible to tell from a graph of course - which is why one does econometrics" (p. F279).
} 
cointegration to model the relationship between corporate bond spreads and interest rates and find evidence of asymmetric short-run and long-run effects of a change in Treasury yields. ${ }^{10}$ Recently, Gilchrist and Zakrajšek (2013) have used event-style regressions to focus on the "default risk" channel connecting the Treasury and corporate markets, and quantify the effects that the announcements of the three LSAP programs had on credit derivative (CDX) indices. Their heteroskedasticity-based identification strategy implies that the unconventional policy measures employed by the Fed to stimulate the economy have lowered the level of credit risk in the economy.

The rest of the paper is structured as follows. Section 2 presents the econometric methodology, describes our data sources and portfolio construction approach, and comments on summary statistics. Section 3 shows preliminary findings based on a singlestate VAR and raises a number of puzzles. Section 4 reports results based on a Markov Switching VAR (MSVAR) model and clarifies when and how some policies may be effective. Section 5 concludes.

\section{Methodology and Data Construction}

\subsection{Markov Switching VAR Models}

The notion that single-state vector autoregressive models may be insufficient to capture endogenous relationships among variables over time has recently become widespread in the empirical macroeconomics literature (see, e.g., Kapetanios et al., 2012), where the presence of instability and (often, recurring) change points has been often recognized and modelled. Because among the models employed to capture such time-varying relationships Markov switching models have played a key role (see, e.g., Hayashi and Koeda, 2013), in this paper we adopt a MSVAR approach.

A $k$-regime $\operatorname{MSVAR}(p)$ process with heteroskedastic components, henceforth shortened as $\operatorname{MSIAH}(k, p)$ (Markov switching intercept autoregressive heteroskedastic) as in Krolzig (1997), can be represented as

$$
y_{t}=v_{S_{t}}+\sum_{j=1}^{p} A_{j, S_{t}} y_{t-j}+\Omega_{S_{t}}^{1 / 2} e_{t} \quad e_{t} \sim N I D\left(0, I_{M}\right),
$$

\footnotetext{
${ }^{10} \mathrm{~A} 100$ bps increase in 10-year Treasury yields is reported to reduce Aaa spreads by $34 \mathrm{bps}$ and Baa spreads by $47 \mathrm{bps}$ in the short-run. In contrast, a $100 \mathrm{bps}$ positive shock to 10-year Treasury yields produces a long-run increase of about $103 \mathrm{bps}$ in Aaa and 118 bps in Baa spreads. To explain these results, Neal et al. (2000) draw on the dynamic capital structure model of Goldstein et al. (2001). An increase in interest rates triggers a decrease of firm leverage below its optimal level. Because in this model capital structure matters, a departure of leverage from its optimum causes an increase in credit spreads. Over time, the firm adjusts back to its optimal debt-equity ratio and the spread increases. See also Joutz et al. (2001) and Lin and Curtillet (2007).
} 
where $S_{t}=1,2 \ldots k$ indicates the regime at time $t, k$ is the number of regimes, $y_{t}$ is a $M \times 1$ vector of endogenous variables, $v_{S_{t}}$ is a regime-dependent $M \times 1$ vector of intercepts, $A_{1, S_{t}}, \ldots, A_{j, S_{t}}$ are the regime-dependent $M \times M$ vector autoregressive coefficient matrices, and the lower triangular matrix $\Omega_{S_{t}}^{1 / 2}$ represents the regime $S_{t}$-specific factor in a regimedependent Choleski decomposition of the covariance matrix $\Omega_{S_{t}}$. Because in general $\Omega_{S_{t}}^{1 / 2}$ is not diagonal, the variables in $y_{t}$ will be simultaneously cross-correlated. Conditionally on the state $S_{t}$, the process described in equation (1) is identical to a standard Gaussian $\operatorname{VAR}(p)$ (to be described below). In practice, however, because state $S_{t}$ is unobservable and follows a $k$-state Markov chain process, the MSVAR process in (1) will be able to generate arbitrary non-normalities and represents a rather flexible dynamic time series process. In particular, we follow the literature (see Ang and Timmermann, 2011) and assume that the unobservable state $S_{t}$ is generated by a discrete-state, homogeneous, irreducible and ergodic, first order Markov chain such that

$$
\operatorname{Pr}\left(S_{t}=j \mid\left\{S_{j}\right\}_{j=1}^{t-1},\left\{Y_{\tau}\right\}_{\tau=1}^{t-1}\right)=\operatorname{Pr}\left(S_{t}=j \mid S_{t-1}=1\right)=p_{i, j} \in(0,1),
$$

where $p_{i, j}$ is the probability of switching from regime $j$ to regime $i$. The transition matrix $P$ that collects the probabilities $p_{1,1} \ldots p_{i, j}$ is called the transition matrix of the Markov chain process. For simplicity, in the following we assume that $P$ is constant over time.

The model in (1) requires the estimation of a number of parameters equal to

$$
K\left[M+p M^{2}+\frac{M(M+1)}{2}+(K-1)\right] .
$$

If $M$ is large, this leads to the estimation of an extremely high number of parameters. As an alternative to a full $\operatorname{MSIAH}(k, p)$, one can estimate a number of simpler models. In a $\operatorname{MSIH}(k, 0)$ (Markov switching intercept heteroskedasticity), only the intercept terms are regime-dependent and $p=0$ :

$$
y_{t}=v_{S_{t}}+\Omega_{S_{t}}^{1 / 2} e_{t}
$$

In a $\operatorname{MSIH}(k, p)$, instead, $p>0$, but the VAR matrices are state-independent:

$$
y_{t}=v_{S_{t}}+\sum_{j=1}^{p} A_{j} y_{t-j}+\Omega_{S_{t}}^{1 / 2} e_{t}
$$

Finally, in a $\operatorname{MSIA}(k, p)$ (Markov switching intercept autoregressive) model the intercept terms and the VAR coefficient matrices are regime-dependent, while the covariances of the error terms are state-independent:

$$
y_{t}=v_{S_{t}}+\sum_{j=1}^{p} A_{j, S_{t}} Y_{t-j}+\Omega^{1 / 2} e_{t}
$$

The $\operatorname{MSIAH}(k, p)$ model in (1) may be estimated using maximum likelihood (ML) methods. Appendix A details the basic estimation steps (or see Hamilton, 1993, 1994, for 
textbook treatments). Under conditions discussed in Krolzig (1997), consistency and asymptotic normality of the ML estimator for a $\operatorname{MSIAH}(k, p)$ may be shown to hold. As a consequence, standard inferential procedures can be used to test statistical hypotheses. For example, standard $t$-tests are used to assess the significance of estimated parameters. Under the assumption of a single regime, $k=1$, the $\operatorname{MSIAH}(k, p)$ model in (1) reduces to a standard $\operatorname{VAR}(p)$ model in its standard (or reduced) form,

$$
y_{t}=v+\sum_{j=1}^{p} A_{j} y_{t-j}+\Omega^{1 / 2} e_{t} \quad e_{t} \sim N I D\left(0, I_{M}\right) .
$$

Because we are interested in understanding the effects of several types of monetary shocks on corporate yields and spreads, in this paper we compute impulse response functions (IRFs). An IRF traces the effects of a one-time shock to one (or more) of the innovations to either (1) or (7) to the current and future values of the endogenous variables. In the case of the dynamic econometric models entertained in our paper, IRFs correspond to classical "counterfactual analyses" popular in the recent literature (see e.g., Chen et al., 2012) that assess what would have happened (in our case, to corporate yields and premia) had a given policy not been undertaken, which we then compare with a baseline prediction which includes the policy. In the case of (7), to construct IRFs, we consider an infinite-order moving average representation $(\operatorname{MA}(\infty))$ of the $\operatorname{VAR}(p)$ (see Cronin, 2013),

$$
y_{t}=\mu+\sum_{j=0}^{\infty} A_{j} u_{t-j}
$$

where $\mu$ is the unconditional mean, computed as $\mu=\left(I_{m}-A_{1}-\cdots-A_{p}\right)^{-1} v$.

To ensure that the correlations among the innovations to the variables included in the VAR are zero, we apply a standard Choleski decomposition, that allows us to decompose the covariance matrix as $\Omega^{1 / 2}\left(\Omega^{1 / 2}\right)^{\prime} \equiv \Sigma=P P^{\prime}$ to re-write the VAR such that the residuals of different equations are uncorrelated. ${ }^{11}$ As is well known, the drawback of this methodology is that, because it forces asymmetries in the system, the ordering of the variables assumes a potentially crucial importance that grows with the magnitude of the contemporaneous correlations of the innovations. Therefore, to avoid an undue influence of the ordering of the variables on our empirical findings, we will re-estimate our models using alternative orderings to assess the robustness of our results. However, due to the

\footnotetext{
${ }^{11}$ Because the covariance matrix $\Sigma$ can be written as $\Sigma=W \Sigma_{e} W^{\prime}$, where $\Sigma_{e}$ is a diagonal matrix with positive diagonal elements and $W$ is a lower triangular matrix with unit diagonal, if we premultiply equation (7) by $B \equiv W^{-1}$ and define $\Gamma \equiv B A_{i}$, we obtain $A y_{t}=v+\Gamma_{1} y_{t-1}+$ $\Gamma_{2} y_{t-2}+\cdots+\Gamma_{p} y_{t-p}+e_{t}$, where $e_{t} \equiv B u_{t}$ has a diagonal covariance matrix $\Sigma_{e}=B \Sigma B^{\prime}$. The infinite-order moving average representation stated above can then be re-formulated as $y_{t}=\mu+\sum_{j=1}^{\infty} \Theta_{j} w_{t-j}$, where the $\Theta_{j}(i)$ coefficients are the impulse response functions to the orthogonal innovations $w_{t}$.
} 
fact that the contemporaneous correlations are not very high in our data, our results seem to be quite stable and only marginally influenced by the changes in the variables ordering. Thus, for the purposes of our analysis, the advantages of a Choleski decomposition by far offset its drawbacks. Moreover, because this identification problem also plagues MSVAR models, we apply the Choleski decomposition to each of the regimedependent covariance matrices. As a general rule, our triangular factorizations follow two criteria: variables to be shocked are placed on top of the ordering, as in Wright (2012); the rest of the variables are ordered on the basis of their residual maturity, with Treasuries preceding corporate bonds.

Because impulse response functions are computed using estimated coefficients, they clearly also reflect estimation error. Accordingly, we construct confidence intervals for the impulse response functions using bootstrapping techniques. The bootstrap method produces confidence intervals that are more reliable and simpler to compute in practice than those based on asymptotic theory (see, e.g., Kilian, 1998). To implement the bootstrap method, each equation is estimated by OLS and a series $\left\{e_{t}\right\}$ of $T$ errors ( $T$ being the sample size) is constructed by random sampling with replacement from the estimated residuals. ${ }^{12}$ The series $\left\{e_{t}\right\}$ and the estimated coefficients are then used to construct $\left\{y_{t}^{1}\right\}$. Finally, the coefficients used to generate $\left\{y_{t}^{1}\right\}$ are discarded and new coefficients are estimated from $\left\{y_{t}^{1}\right\}$, obtaining a new time series of residuals $\left\{e_{t}^{1}\right\}$. The resampled impulse response function indexed as 1 is computed from the new estimated coefficients. At this point, starting from the $\left\{e_{t}^{1}\right\}$, the algorithm is re-started to construct $\left\{y_{t}^{2}\right\}$ to estimate new coefficients and obtain both new residuals $\left\{e_{t}^{2}\right\}$ and a re-sampled impulse response function indexed as 2 . This process is iterated a total of $M$ times. When this process is repeated for a sufficiently large number of times, the resulting set of $M$ simulated impulse response functions can be used to construct the confidence intervals. For example, a 95\% confidence interval is the one that excludes the highest and the lowest $2.5 \%$ of the bootstrapped, re-sampled IRFs. An impulse response function is considered statistically significant if zero is not included in the bootstrapped confidence interval (see also Enders, 1995).

It is possible to extend the concept of IRF to non-linear models by defining a generalized IRF (see, e.g., Koop et al., 1996), with reference to a MS framework. For concreteness, we focus on the estimation of IRFs for a $\operatorname{MSIH}(k, p)$ model, where the coefficient matrix is not regime-dependent, because this type of MS models turns out to dominate all

\footnotetext{
12 When re-sampling the residuals, one has to take into account the fact that these in general will be correlated across different equations.
} 
alternatives in the empirical results that follows in Section 3, while the $\operatorname{MSIH}(k, p)$ case is relatively easy to deal with. In general, an $h$-step-ahead IRF is defined as

$$
I R_{\Delta e}(h)=E\left[Y_{t+h} \mid y_{t}\left(\omega^{\prime}\right)\right]-E\left[Y_{t+h} \mid y_{t}(\omega)\right],
$$

where the sample path $y_{t}\left(\omega^{\prime}\right)$ is equal to the sample path $y_{t}(\omega)$ with the exception of the initial value of $y_{t}$, which has been perturbed by a shock $\Delta e$ (see Potter, 2000). In practice, an IRF measures the difference between the conditional expectation of $Y_{t+n}$ at time $t$ in case $y_{t}$ has been subject to a shock and the conditional expectations of $Y_{t+n}$ at time $t$ in case $y_{t}$ has not been shocked. This definition can be generalized to fit a Markov switching framework. In practice, we can rewrite (9) as (see Hayashi and Koeda, 2013):

$$
I R_{\Delta e}=E\left[Y_{t+h} \mid \xi_{t}, e_{t}+\Delta e ; Y_{t-1}\right]-E\left[Y_{t+h} \mid \xi_{t}, e_{t} ; Y_{t-1}\right]
$$

In a regime-switching framework an $h$-step-ahead IRF depends on the state prevailing at time $t$ when the shock occurs. The problem in the computation of a Markov switching IRF is that the regimes are not observable. Noticeably, because we analyze $\operatorname{MSIH}(k, p)$ models where the VAR matrix is not regime-dependent, we only need information about the state prevailing at the time the shock occurs. Even though other calculations are possible (Monte Carlo techniques to simulate the ergodic distribution of regimes, or assuming equal probabilities across regimes), in this paper we assume that the regime prevailing when the shock occurs is known. Despite the fact that it relies on one partially reasonable assumption (observable regimes), this methodology is useful to our analysis as it allows us to examine the effects of a shock conditioning upon the realization of a given state. ${ }^{13}$ The confidence intervals for the IRFs are computed with Monte Carlo simulation techniques exploiting the (asymptotic) normality of the ML estimators of conditional mean parameters in both the cases of $k=1$ and $k>1$. We sample randomly conditional mean parameters from this distribution a sufficiently large number of times (in the paper we set $M=10,000$ throughout) and we compute IRFs.

To select the model structures-including the number of regimes and the number of lags in the case of (1), and the number of lags in the case of (7)-we conduct an extensive specification search using three information criteria: the Akaike information criterion, the Schwarz criterion and the Hannan-Quinn criterion. This approach allows us to adopt the most parsimonious models and thus avoid the problems associated with over-fitting, such as the typically observed deterioration in (out-of-sample) mean square forecast errors.

\footnotetext{
13 We have also computed MS IRFs when the initial regime is unknown. In general, because in these cases the responses are probability-weighted averages of state, no significant effects can be detected even in the MS case. Complete results are available from the author(s) upon request.
} 


\subsection{The Data: Cleaning and Filtering}

One of the main difficulties that plague fixed income research, for instance in comparison to equity market research, is that bond markets are far more illiquid and less transparent. Bessembinder et al. (2009) report that the average bond trades only 52 days per year and, conditional on trading, approximately 4 times per day. Many existing studies rely on indices of corporate bond yields, such as those produced by Moody's or by Barclays (see, for example, Neal et al., 2000; Longstaff, 2010). Unfortunately, the use of those indices has several drawbacks, including the fact that they are generally constructed considering both callable and non-callable bonds. This may have a significant impact on the behavior of the yields, because the value of the embedded short call option increases when the price of the bond rises because when interest rates fall, financing can be obtained at a lower cost. As a result, the price of a callable bond tends to increase less compared to the price of an otherwise comparable non-callable bond. Consequently, given the goals of our analysis, we place great emphasis on constructing our own corporate bond portfolios.

The introduction of the Trade Reporting and Compliance Engine (TRACE) system by the National Association of Securities Dealers (NASD, currently known as the Financial Industry Regulatory Authority, FINRA) has significantly enhanced the transparency of the U.S. corporate bond market. ${ }^{14}$ Consequently, we rely on TRACE to construct from scratch our corporate yield and spread time series. Considering that the implementation of TRACE was a gradual process and it was expanded to cover almost all publicly traded bonds-including non-investment-grade bonds-only by October 2004, our sample starts from that date. Accordingly, we collect a sample of 68,813,471 corporate bond trades between October 1, 2004 and December 31, 2012. The construction of our data series using trade details from TRACE requires an accurate filtering and cleaning of the data to remove incorrect recordings and incomplete records. As pointed out by DickNielsen (2009), about 7.7\% of TRACE records contain errors. Moreover, trades on a "when-issued" basis and those with special sale conditions have to be eliminated because their price is unlikely to reflect the current market conditions, potentially introducing biases in the analysis. ${ }^{15}$ Appendix B describes such filters and transformation in detail. In essence, the first step in filtering the raw data is to eliminate trade cancellations, corrections and reversals; the second step deletes those trades the reported price of

\footnotetext{
${ }^{14}$ Starting on July 1, 2002 the details of each over-the-counter (OTC) transaction, such as a CUSIP identifier, execution date and time, yield, volume, and sale conditions have to be reported.

${ }^{15}$ Trades on a when-issued basis are those referring to a security that has not been issued yet, but has received the authorization to be issued. These trades are settled if and when the security is actually issued. Despite the fact that the TRACE system does not cover primary markets, whenissued trades can be found in the data as the result of corporate events (e.g., re-reorganizations).
} 
which includes commissions or that were performed under particular market conditions (e.g., outside of market hours) or that are classified as special price observations. All these trades are identified by specific indicators in the dataset, so we use an algorithm that searches for reports that contain these flags and eliminates such transactions. Finally, trades with a volume lower than $\$ 50,000$ are discarded. The filtered dataset is then merged with the CUSIP Service Bureau database to retrieve information such as the maturity of the bond, the coupon rate, the payment frequency, and the ISO CFI code that is useful for identifying a number of bond characteristics such as the presence of embedded options. Indeed, callable, putable and convertible bonds have to be eliminated from the sample because of the reasons explained above. Finally, the remaining trades are merged with the Mergent FISD Database in order to assign to each traded bond the most recent available rating.

\subsection{Preliminary Evidence on Corporate Bond and Treasury Yields}

The cleaned, filtered and merged dataset is used to construct four series of weekly yields. The observations are divided into portfolios according to their rating and maturity: (1) investment-grade short-term bonds (henceforth IGST), (2) investment-grade long-term bonds (IGLT), (3) non-investment-grade short-term bonds (NIGST), and (4) noninvestment-grade long-term bonds (NIGLT). A bond is classified as short-term if its remaining time to maturity is less than 5 years and long-term otherwise. Moreover, a bond is non-investment grade (NIG) if its rating is below BBB- (Standard \& Poor's) or Baa (Moody's); otherwise a bond is of investment grade (IG). We limit ourselves to four corporate portfolios because the adoption of MSVAR methodologies implies considerable proliferation in the number of estimable parameters. ${ }^{16}$

The weekly yield series for each of the four portfolios are constructed as follows. YIELD $D_{t, j}$ is the average yield for all the bonds traded in week $t$ and belonging to portfolio $j$. If there is more than one observation for a bond within the same week, only the last transaction in the week is taken into account to compute the portfolio average yield for the week. ${ }^{17}$ We thus obtain four weekly (Friday-to-Friday) yield series from October 8, 2004 to December 28, 2012 (a total of 430 observations per series). These are plotted in Figure 1. The figure is dominated by the spike in corporate yields-especially the NIG ones-in

\footnotetext{
${ }^{16}$ As TRACE is extended past the end of 2012, it will be interesting to expand the number of corporate bond portfolios to exceed four, for instance, by creating a distinction among (truly) short- (less than 18 months), medium-, and long-term bonds, or also grouping bonds into junk (say, B rating and below), non-investment, and investment-grade status.

${ }^{17}$ For trades whose yield is missing in TRACE, we resort to direct computation: knowing the coupon and its frequency, the issue date and the residual time-to-maturity, we calculate the yield.
} 
correspondence to the financial crisis of 2008-2009 and to some minor extent the European sovereign debt crisis of the Summer 2011 and S\&P's downgrade of U.S. Treasury bonds in August 2011 (but only for NIGST paper).

Table 1 presents summary statistics for corporate bond yields. A comparison among the mean yields-to-maturity of the different series suggests that while the term structure of IG bonds is on average upward sloping, the one for NIG bonds is downward sloping. This is in line with the empirical findings of a number of studies (e.g., Sarig and Warga, 1989; Joutz et al., 2001). In addition, short-term yields tend to be more volatile than long-term ones for both the IG and NIG buckets. All four series show positive skewness and excess kurtosis, which is consistent with the presence of regimes in their conditional density. The yields of bonds in the same rating cluster but in different maturity buckets are highly and positively correlated. The correlation is instead lower for bonds which are in the same maturity cluster but which have different ratings. This feature can be interpreted as a validation of the idea that financial markets are partially segmented.

In addition to these corporate yield series, we also construct the corresponding credit spread series. For each trade in the sample, the associated spread is calculated as the difference between the yield of the bond and the yield of a Treasury with a maturity which (approximately) matches the remaining life of the corporate bond. Importantly, this is done on a trade-by-trade basis to minimize the risk of missing out on important fluctuations in the Treasury series. $S P R E A D_{t, j}$ is then the average spread for all the bonds traded in week $t$ and belonging to portfolio $j$. It is worth noting that this methodology to calculate spreads is more accurate than simply taking the difference between corporate yield averages and Treasury rate (see Lin and Curtillet, 2007, for a related discussion).

Table 2 reports the main statistics for corporate bond spreads. Similar to yields, the spreads display strong evidence of non-normality. All four series have positive skewness and positive excess kurtosis. Also similarly to yields, short-term spreads show a higher volatility relative to long-term spreads. Interestingly, the correlations are higher than for yields, both within the same rating cluster and between different rating classes. This suggests that spreads not only incorporate default risk, which depends on the credit quality of the issuer, but also a risk premium, which reflects general market conditions.

The Treasury yield curve is summarized by the 1-month, 1-year, 5-year, and 10-year constant maturity Treasury yields. ${ }^{18}$ These yields are plotted in Figure 2. In addition to

\footnotetext{
${ }^{18}$ Constant-maturity yields are commonly used as proxies for Treasury yields. These yields are interpolated by the U.S. Treasury Department from the daily yield curve, which is based on the daily closing market bid yields on securities actively traded in the over-the-counter market. The interpolation allows us to obtain the yield at any point of the yield curve also if there are no
} 
this approach, we also use the method suggested by Littermann and Scheinkman (1991) to decompose the information embedded in the Treasury term structure. Littermann and Scheinkman observed that a three-factor model is able to explain most of the variability in the Treasury yield curve. To estimate our three-factor model we extract the first three principal components from the matrix containing the 1-, 3-, 6-month, 1-, 2-, 3-, 5-, 7-, and 10 -year constant-maturity Treasury yields. These eight yield series are retrieved from the Federal Reserve of St. Louis FRED II data repository and also cover the period from October 8, 2004 to December 28, 2012. As suggested by Littermann and Sckeinkman (1991), these three factors can be regarded as the level, the slope and the curvature of the Treasury term structure. This classical interpretation is confirmed by our results in Figure 3, where we have plotted the factor loadings of the first three components. A change in the level represents a parallel change in yields. The slope is the steepness of the yield curve, i.e., the difference between short-term and long-term bond yields. An increase (decrease) in the slope of the Treasury yield curve means that the yields of longer-term bonds are increasing faster (slower) than the yields of shorter-term bonds or that they are falling less (more) rapidly, or even that long-term yields are rising (falling) while short-term yields are falling (rising). The curvature is a measure of the convexity of the yield curve. A shock to this factor mostly affects medium-term yields, causing the curve to become more (less) "hump-shaped". Our first three principal components explain $99.92 \%$ of the total variance (see Table 3). The first component alone (the level) accounts for $95.19 \%$ of the total variability.

Table 4 presents summary statistics for 1-month, 1-, 5-, and 10-year Treasury yields. A comparison among means for different maturities reveals that the Treasury term structure is, on average, upward sloping, as one would expect. This is confirmed by the statistics in Table 5, which summarizes the characteristics of the three factors that decompose the information implicit in the Treasury yield curve. Indeed, it can be noticed that the slope is, on average, positive. Also, the distribution of Treasury yields is strongly non-normal. All Treasury yields, with the exception of the 10-year yield, are characterized by a slightly positive skewness. In addition, they have a kurtosis lower than 3 (i.e., thinner tails than a normal distribution). Correlations are high among all the series and tend to be higher for contiguous maturities. In particular, the 1-month and the 1-year Treasury yields show a correlation of almost 0.99 . As shown in Table 5, the level and the slope tend to be negatively correlated, suggesting that when the general level of interest rates falls (rises) the difference between short-term and long-term yields widens (shrinks).

outstanding bonds with that particular time-to-maturity. For the purposes of our analysis we use weekly (Friday-to-Friday) constant-maturity Treasury yields available from the Center for Research on Security Prices (CRSP) at the University of Chicago. 


\section{Preliminary Empirical Results under a VAR Model and a Puzzle: When Monetary Policies Cannot Be Transmitted to Corporate Bond Markets}

We start our empirical investigation by estimating two simple reduced-form VARs-one to study the effects of monetary policies on corporate yields, the other to assess their effects on corporate spreads. The first single-state model, henceforth referred to as the yield-VAR, includes eight endogenous variables: the four corporate yield series computed according to the methodology described in Section 2.2 (investment-grade short-term, investment-grade long-term, non-investment-grade short-term, and non-investment grade long-term) and four Treasuries series (1-month, 1-, 5-, and 10-year yields). The second single-state framework, henceforth identified as the spread-VAR, includes the four corporate spreads series along with Treasury yields.

As a preliminary step, a specification search is conducted to select the VAR lag order, $p$. In practice, we compare the scores that alternative values of $p$ imply under three information criteria: the Akaike Information Criterion (AIC), the Schwarz Criterion (SC), and the Hannan-Quinn criterion (HQ). These are penalized measures of fit that trade off the precision of fit and the parsimony of a model. An unreported table indicates that the selected VAR order varies according to the criterion considered. ${ }^{19}$ However, because a literature exists (see, e.g., Lütkepohl, 1991) that emphasizes the advantages of SC over the remaining criteria, we select $p=1$ for both the yield-and spread-VAR models. $p=1$ implies the estimation of 108 parameters, leading to a satisfactory saturation ratio of 31 .

Table $\mathrm{C} 1$ in the Appendix reports the estimation results for the yield-VAR, while Table $\mathrm{C} 2$ reports the results for the spread-VAR. For all conditional mean coefficients we also report in parenthesis the $p$-value for (robust, HAC) $t$-test of the null that the parameter is zero. For the yield-VAR, roughly $50 \%$ of the coefficients are significant. In particular, the corporate yield series have significant forecast power for each other, while Treasury yields do not appear to have significant predictive ability for corporate yields. In contrast, for Treasury yields many of the $t$-statistics for the lagged corporate yields are significant at a $1 \%$ or $5 \%$ level, indicating that corporate yields have some forecast power for Treasuries. Finally, each Treasury yield series shows significant predictive ability for the other Treasuries. The findings are similar in Table $\mathrm{C} 2$ in the Appendix, where approximately half of the coefficients are significant. In addition, Treasury yields tend to not have a high explanatory power for credit spreads, while IG spreads have a high

\footnotetext{
${ }^{19}$ For both the yield- and spread-VARs, AIC selected instead a richly parameterized VAR(10), which implies the estimation of 684 parameters, leading to a saturation ratio (the number of observations per estimated parameter) of only 5.5. The HQ criterion is minimized by a VAR(3) model, which implies the estimation of 236 parameters, with a saturation ratio of 14.6.
} 
predictive ability for 1-month, 5-year and 10-year Treasuries. Finally, each corporate spread series can forecast other spreads.

Using the estimated parameters, we proceed to compute IRFs under three monetary policies: a conventional monetary expansion, a QE-type policy, and an OT-type policy. As discussed in the Introduction, where these policies have been formally defined, these are simulated as shocks to Treasury yields. In particular, we study the effects of onestandard-deviation shock to appropriate combination of Treasury yields (see, e.g., Ang and Piazzesi, 2003; Wright, 2012).

Appendix C reports detailed IRF estimates with bootstrapped confidence $95 \%$ intervals and distinguishes between the effects of conventional monetary policies, of QE, and of OT. Here we provide a brief summary of the key findings and of the ensuing puzzles for an understanding of the impact of monetary policies on corporate bonds. Appendix C reveals a startling result: a conventional, expansionary monetary policy-captured as a one standard deviation reduction in the 1-month T-bill rate leads to a general increase, rather than a decrease, in corporate rates. The most noticeable increase, both in terms of magnitude, persistence, and statistical significance is the one affecting NIGST yields. The effects of a conventional, rate-based expansionary monetary policy on corporate spreads are similar to those on yields. A decline in the 1-month Treasury yield causes a general increase in spreads, which is especially pronounced for NIG yields. This means that in a single-state VAR model, it is the lower-rated, weaker firms that will record an increase of the risk premia paid on the bond markets. The effect is again more pronounced for shortterm spreads than for long-term ones, and this is true for both investment and NIG corporates. Interestingly, short-term yields and spreads tend to be more reactive than long-term ones. A possible explanation for this finding is that long-term assets are typically preferred by buy-and-hold investors (such as pension funds). These have specific maturity preferences and are less prone to frequent rebalancing of their portfolios. The shape of the IRFs is otherwise similar to the ones observed for the yieldVAR model: hump-shaped for NIG spreads and strictly declining for IG spreads.

This empirical evidence is puzzling because it suggests that-at least in unconditional, average (single-state) terms-conventional monetary measures may struggle in producing strong and desirable effects on the (debt) cost of capital of firms. The existence of a negative relationship between credit spreads and Treasury yields is well documented in the finance literature and in fact several explanations have been discussed. For instance, Duffee (1998) finds that a decline in the level of Treasury yields triggers an increase in corporate spreads, which becomes more pronounced as the credit quality decreases. He comments that these findings are consistent with the contingent claim 
model of firm valuation proposed by Longstaff and Schwartz (1995), in which a decrease in Treasury rates increases the probability of bond default because of the effect that it has on the drift of the asset value process. ${ }^{20} \mathrm{Wu}$ and Zhang (2008) have also researched the relationships between credit spreads and macroeconomic factors and found that an increase in inflation is likely to increase spreads. These results clearly have problematic implications for the chances of standard, rate-based expansionary policies to provide relief to the corporate sector-at least as far as the cost of capital is concerned-which may come under pressure during a recession (or worse, a financial crisis).

As far as QE is concerned, because this policy implies the purchase of long-term Treasuries, we simulate it as a one-standard-deviation reduction in the 10-year Treasury yield. Appendix C and Figure 4 confirm the puzzling evidence obtained for conventional shocks: a negative innovation to the 10-year Treasury generates a generalized increase in corporate yields. While the effect is modest for IG bonds and not significant for long-term ones, the increase is more pronounced for NIG bonds. The responses of NIGST vs. NIGLT yields show opposite patterns. As one would expect in light of the literature, QE lowers the level of Treasury yields and reduces the slope of their term structure. Moreover, the effects of $\mathrm{QE}$ on corporate spreads are generally neither particularly pronounced nor persistent, with the noticeable exception of NIGST. For this segment of the market, the policy reaches a plausible goal of lowering the risk premia and of favoring a re-allocation of resources to lower-rated firms' investments.

Finally, we simulate OT as a reduction in the 10-year Treasury yield accompanied by a contemporaneous increase of the 1-month T-bill rate. The results in Appendix $\mathrm{C}$ and Figure 5 are consistent with those for conventional policies: under a simple single-state VAR framework, an expansionary, OT-like policy yields counterintuitive results: the responses of corporate yields to OT are statistically significant only for the first 1 or 2 weeks, are modest and often close to zero, and often carry the wrong sign, as yields increase. Moreover, bonds of higher quality tend to be the least affected by monetary policy changes as the effect on NIG bonds is more pronounced than on IG ones. ${ }^{21}$ Results are instead more in line with expectations in the case of corporate spreads as OT generates a general and persistent decrease of all the corporate spreads. In particular, the policy is able to produce a substantial and persistent decrease in NIGST spreads. Their

\footnotetext{
20 This negative relationship is indeed predicted to be more pronounced for non-investmentgrade corporate bonds (see Longstaff and Schwartz, 1995).

${ }^{21}$ Although one may expect to see the opposite given the nature of OT, i.e., rising short-term yields and decreasing long-term ones, these results may be accounted for by the peculiar shape of the non-investment-grade term structure. Indeed, as discussed in Section 2.3, our data document an inversion of the NIG yield curve.
} 
IRF remains statistically significant for longer than 5 months. Although smaller in comparison, the reduction is significant and persistent also for NIGLT spreads. This evidence is interesting because the literature reports conflicting findings with respect to the relationship between the slope of the Treasury term structure and corporate spreads. In contrast to our results, some studies, such as Duffee (1998), find a negative relationship between corporate spreads and the riskless term structure. Joutz et al. (2001) find that the relationship is positive at least for some rating and maturity clusters. These contrasting results may suggest that the nature of the relationship may change over time according to the general conditions of the economy. We will return to this issue in the next section, where we extend our analysis to allow for different regimes.

Because our earlier findings may have been influenced by a number of technical choices, we have also performed a range of robustness checks to assess the sensitivity of the surprising single-state results to our assumptions. In particular, similarly to Hamilton and $\mathrm{Wu}$ (2012), we have also re-estimated the yield-VAR and the spread-VAR models replacing the yield series that have been used to decompose the Treasury yield curve with the three factors-level, slope and curvature-isolated and discussed in Section 2.3. Estimated VAR(1) models similar to those in Tables 6 and 7 reveal that a vast majority of the conditional mean coefficients relating the slope and curvature factors to corporate yields and spreads fail to be statistically significant at any acceptable confidence level for both the yield-VAR and the spread-VAR. However, and disregarding the fact that because of the considerable parameter uncertainty the IRFs are generally imprecisely estimated and confidence intervals rarely exclude zero, most of the results of the IRF analysis are consistent with what has been observed above. Thus, the (lack of, or perverse) effects of the policies reported above do not depend on the choice of a particular approach to simulating a specific policy.

As already discussed in Section 2.1, we have also experimented with a range of alternative Choleski decompositions but, due to the fact that the residual contemporaneous correlations in the VAR(1) are not very high, our results are robust to changes in the variable ordering.

\section{Regime-Dependent Monetary Policy Transmission to Corporate Bonds}

As discussed in Section 3, a single-state VAR framework may be insufficient to represent the structure of the data, especially given that financial markets are characterized by well-known patterns of instability, structural breaks, regimes, etc. (see, e.g., Ang and Timmermann, 2011). For instance, Cronin (2013) finds considerable instability in his 
single-state VAR-based decomposition, especially with reference to the Great Financial Crisis when monetary aggregates impact asset prices much more than in "normal" times, but limits himself to a rolling-window-style analysis. Wright (2012) repeats his VAR analysis with reference to pre- and post-crisis periods and notices that, not surprisingly, monetary policy shocks operate on different points of the yield curve in the pre-crisis sample. In this section we estimate a range of MSVAR models for yield and spread series.

\section{1. $\quad$ Model Selection}

To specify a MS model one has to select not only the appropriate number of lags, but also the number of regimes. In addition, as illustrated in Section 2.1, a number of alternative models are possible, depending on which parameters are allowed to switch. We analyze three types of models: $\operatorname{MSI}(k, p)$, where only the intercept terms are regime-dependent, $\operatorname{MSIH}(k, p)$, where both the intercept terms and the covariance matrix are regimedependent, and $\operatorname{MSIAH}(k, p)$, where also the vector autoregressive parameters are regime-dependent. We consider a number of lags up to 2 and a number of regimes up to 3. The choice to not restrict $k=2$ is consistent with the findings of Guidolin and Timmermann (2009) that at least a three-regime specification is needed when dealing with U.S. fixed income market. Moreover, a model with $k \geq 3$ would be too large to be estimated with a sample of 3,440 observations.

We use an adjusted (to protect against nuisance parameter problems, see Davies, 1977) likelihood ratio (LR) test to see whether a multi-state framework is appropriate. For both the yield-MS and the spread-MS models, the LR test always rejects the null hypothesis of $k=1$ at any conventional confidence level. Consequently, we conclude that $k>1$ is appropriate. Furthermore, using Akaike, Schwartz and Hannan-Quinn criteria, we select a $\operatorname{MSIH}(3,1)$ model for both yields and spreads. ${ }^{22}$

\subsection{A Three-State MSIH VAR(1)}

The selected $M S I H(3,1)$ model of the form specified in equation (5) is estimated for both the yield and the spread series. As described in Section 2.1, $\operatorname{MSIH}(3,1)$ models have regime-dependent intercepts and covariance matrix, but regime-independent VAR matrix. In a MS model the variables affect one another through three channels: the dependence of each variable on lagged values of the others, the contemporaneous correlations, and the dependence of all the variables upon a unique Markov chain, as postulated in (5). However, because we estimate $\operatorname{MSIH}(3,1)$ models which do not allow

22 The details of all tests performed for model selection are available upon request. 
for regime-dependent autoregressive parameters, the linear relationships among the variables are stable over time.

The estimation results for the yield-MSIH(3,1) and the spread-MSIH(3,1) models are reported in Tables 6 and 7, respectively.23 For each of the estimated coefficients we report in parenthesis the $p$-value of a $t$-test that the parameter is zero. Similarly to singlestate VARs, approximately one half of the coefficients are significant for both the yield$\operatorname{MSIH}(3,1)$ and the spread-MSIH(3,1) models. Importantly, the vast majority of the statespecific intercepts are significant at the $1 \%$ or at least $5 \%$ level for both the yield$M S I H(3,1)$ and the spread-MSIH(3,1) models. Moreover, the intercept is always significant in at least one of the regimes. Treasury yields show forecast power for each other and for both long-term yields and spreads. Both corporate yields and spreads show predictive ability for Treasuries. In addition, the cross-linkages between the yields of bonds in the same rating classes but in different maturity clusters are always significant, and this pattern holds for spreads as well.

Tables 8 and 9 also show the regime-specific unconditional means of the variables. These means represent expected values under the assumption that regime $i$ will prevail forever. The regime-specific unconditional mean for regime $S$ is computed as

$$
\mu_{S}=\left(I_{m}-A_{1}\right)^{-1} v_{S}
$$

Clearly, such unconditional means exist only if the $\operatorname{MSIH}(3,1)$ is stationary. We calculate the eigenvalues of matrix $A_{1}$ and their modules. Since for both the yield-MSIH(3,1) and the spread $M S I H(3,1)$ none of the modules lies outside the unit circle, $A_{1}$ is stable and the $\operatorname{MSIH}(3,1)$ models are stationary (in all regimes). The regime-specific unconditional means will be used in Section 4.3 to provide an economic interpretation to regimes. ${ }^{24}$

\subsection{Economic Interpretation of the Regimes}

${ }^{23}$ The tables also show the pseudo- $R^{2}$ computed as $R^{2}=1-\left[\sum_{t=1}^{n} \sum_{i=1}^{3}\left(y_{t}-\hat{y}_{i, t}\right)^{2} \hat{\xi}_{i, t}\right] /$ $\left[\sum_{t=1}^{n}\left(y_{t}-\bar{y}\right)^{2}\right]$, where the $\hat{\xi}_{i, t}$ are estimated smoothed probabilities. Similarly to the singlestate VAR, the value of the pseudo- $R^{2}$ is high for the majority of the equations in both the yieldmodel and the spread-model.

24 Unfortunately, the spread-MSIH(3,1), despite being stationary, is near-unit root. For this reason its regime specific unconditional means are difficult to interpret. We adopt an alternative computation of regime-specific long-run values. First of all, we calculate the sample means of our time series. Secondly, we compute the one-step-ahead forecast, $y_{t+n}=v_{i}+A_{1} y_{t+n-1}$, for $n=1, \ldots, 13$ under the assumption of remaining in regime $i$ over time. To initialize the estimate, we set $y_{t}$ equal to the vector that collects the historical sample means from our data. Finally, we compute the averages of the results, which will be used instead of the regime-specific unconditional means to interpret the regimes in the spread-MSIH(3,1) framework. 
In this subsection we provide an economic interpretation of the regimes, jointly analyzing the yield-MSIH(3,1) and the spread-MSIH(3,1) estimated frameworks. Tables 6 and 7 report the transition matrices while Figures 6 and 7 show smoothed probabilities.

In the yield-MSIH $(3,1)$ model, regime 1 is the most persistent of the states, as it has a "stayer" probability (i.e., the probability of remaining in the regime for an additional period) of 0.99 . The average duration of the regime is approximately 22 months and its ergodic probability is $57 \%$. This regime is characterized by low means for both corporate and Treasury yields. In addition, these means imply that both corporate and Treasury rates have an upward sloping term structure. All volatilities are low both for IG corporate and Treasury yields. For example, in regime 1 the 1-month Treasury yield has an annualized volatility of only $0.02 \%$, in contrast to $0.12 \%$ in regime 2 and $0.33 \%$ in regime $3 .{ }^{25}$ On the contrary, the volatility of NIG yields is higher than in regime 2 , albeit lower than in regime 3. For example, NIGST yields display an annualized volatility of $1.58 \%$ in regime 1 , of $0.54 \%$ in regime 2 and of $4.37 \%$ in regime 3 . The pairwise correlations of VAR innovations are in general quite low in this state. Consequently, we can consider regime 1 as a persistent and tranquil regime characterized by low yields and low volatilities.

Regime 2 is also rather persistent, even if less than regime 1 is: the "stayer" probability is 0.97. The average duration of the state is equal to approximately 7 months and its ergodic probability is $33 \%$. This regime is characterized by high means on both corporate and Treasury yields. While the term structure of IG and Treasury yields is upward sloping, NIGST rates are on average higher than long-term ones, thus signalling an inversion of the yield curve. As hinted at above, volatilities are higher than in regime 1 for high-quality assets, but lower for riskier assets (i.e., NIG bonds). Finally, pairwise correlations of innovations are slightly higher than in regime 1 and generally positive. Thus, this regime identifies a bond market characterized by high yields and high volatilities.

Finally, regime 3 is quite peculiar: mean corporate yields peak (reaching an annualized level of $29.02 \%$ in the case of NIGST, although this regime has the duration much lower than one year) while Treasury yields are extremely low or even negative (which has occurred during the 2008-2009 financial crisis). In addition, the term structure of NIG yields is inverted. The volatilities are very high and innovation correlations between Treasuries and corporates are generally negative. The average duration of this state is only 6 weeks and its ergodic probability is $10 \%$. Clearly, this state is less persistent than

\footnotetext{
${ }^{25}$ For ease of comparison, all means and volatilities are expressed in annualized terms even when the duration of the regime is less than one year.
} 
the others: its "stayer" probability is 0.83 . The peculiarities of this regime reveal that it can be interpreted as a state of crisis: during market crashes investors tend to "fly to quality", i.e., they transfer their wealth from high-risk/high-return assets to those that are considered "safe", such as Treasuries. For this reason, corporate yields, and in particular risky NIGs, skyrocket. In contrast, the yields of low-risk assets become low, which our model captures as short-lived, negative unconditional means. This is particularly true for Treasuries, which are generally considered the safest among all assets. ${ }^{26}$

Similarly to the yield-MSIH(3,1) model, regime 1 in the spread-model is characterized by generally low Treasury yields, while regime 2 is characterized by high Treasury yields. In fact, corporate spreads tend to be higher in regime 2 than in regime 1. For example, the mean of NIGST is equal to $8.53 \%$ in regime 1 and to $7.45 \%$ in regime 2 . On the contrary, the mean of 1 -month T-bill rates equals $1.76 \%$ in regime 1 and $2.02 \%$ in regime 2 . Regime 1 exhibits higher volatilities and higher innovation correlations than regime 2 does. For example, NIGST spreads have a volatility of $2.15 \%$ in regime 1 , but of only $0.91 \%$ in regime 2 . In addition, the correlation between the innovations to NIGST spreads and 1-month T-bills equals -0.11 in regime 1, whereas it is only -0.07 in regime 2.

Finally, regime 3 is characterized by high means, high volatilities and high correlations. This is particularly evident for NIG corporate bonds. Indeed, the mean of NIGST spreads reaches an annualized level of $12.42 \%$ and their volatility is equal to $3.74 \%$. Regime 2 is by far the most persistent of the three states: its "stayer" probability is 0.96 . In addition, it has an average duration of approximately 5.5 months and an ergodic probability of $68 \%$. Regimes 1 and 3 are instead less persistent, as their "stayer" probabilities are equal to 0.88 and 0.85 , respectively. Furthermore, they have an average duration of 8.59 and 6.87 weeks and an ergodic probability of $17 \%$ and $15 \%$, respectively.

Thus, regime 1 is characterized by low rates and high spreads, while regime 2 exhibits high rates and low spreads. The existence of an inverse relationship between credit spreads and Treasury yields is well documented in the literature (e.g., Duffee, 1998, and Lin and Curtillet, 2007) and it is also consistent with the findings presented in Section 3. Moreover, many authors who have employed MS models document the presence of a highly persistent regime in which rates are stable and characterized by low means and low volatilities and one in which the opposite is true (see Guidolin, 2012). The behavior of the spreads, instead, is similar to the one that has been empirically observed for stock risk premia: volatility tends to be high when means are low. Finally, regime 3 exhibits

\footnotetext{
${ }^{26}$ Obviously, nominal yields are bounded below by zero. However, given that we compute the regime-specific means under the counterfactual assumption that a particular regime is going to prevail forever, we can estimate negative Treasury yields.
} 
peculiar characteristics, such as flight-to-quality and a peak in volatilities and correlations, which are typical in times of crisis (see, for example, Longstaff, 2010). A scrutiny of the smoothed probabilities confirms this interpretation. Indeed, for both the yield-MSIH $(3,1)$ and the spread-MSIH(3,1) models the smoothed probabilities of regime 3 peak in the period October 2008 - October 2009, which coincides with the outburst of the financial crisis. In the remainder of the paper we refer to regime 1 as low rates/high spreads state, to regime 2 as high rates/low spreads state and to regime 3 as crisis state.

We next estimate IRFs for the three types of shocks that we have already used in Section 3 to represent a conventional expansion, QE and OT, respectively. Figures 8 through 10 report the IRFs for the yield-MSIH(3,1) model, while Figures 11 through 13 show IRFs for the spread-MSIH(3,1) model. The graphs show the responses, along with $95 \%$ confidence bands, up to 26 weeks after policy shocks. These responses are calculated assuming that the initial regime is known, which assumes that policymakers can detect with sufficient accuracy the nature of the current state. However, such an assumption seems to be comfortably supported by the shapes in Figures 6 and 7, where the regime probabilities seem to be usually close to 0 and 1 , with rare cases of uncertainty.

\subsection{Effects of Conventional Monetary Policies}

We first study the effects of an expansionary monetary policy simulated as a onestandard-deviation negative shock to the 1-month T-bill rate. The analysis of the IRFs in the $\operatorname{MSIH}(3,1)$ framework (Figure 8) indicates that the effects of a monetary expansion on yields depend on the regime that prevails at the time in which the policy is implemented. In particular, during a crisis, the effects of a rate-based policy tend to be more pronounced than in the other regimes for all corporate yields, especially the shortterm ones. However, these effects go in a direction opposite to the one desired by the policymakers, i.e., to lower the borrowing costs for businesses and households. In fact, in times of crisis a conventional, expansionary policy causes an increase of about 51 bps in NIGST yields and of 13 bps in long-term ones. Although relatively smaller, the effect is positive also for long-term bonds: NIG yields increase by 11 bps and IG yields rise by 5 bps. Long-term bonds imply smaller responses than short-term ones. Even though it tends to decline, the policy effect remains significant for at least one month following the shock. The response of short-term yields remains significant for more than 4 months.

In contrast, the effect of a monetary expansion in the high rates/low spreads regime consists of a reduction of corporate yields, with the important (to policymakers, we speculate) exception of NIGST yields. The latter tend to increase by about $3 \mathrm{bps}$, but the responses are only significant up to 3 weeks after the shock. Instead, IGST yields decrease 
by about 4 bps and long-term ones by approximately 3 bps. Finally, NIGLT corporate yields fall by about 5 bps. Even when statistically significant, these effects are however very small and hardly credible in terms of their impact on real economic conditions. Thus, in this regime, monetary policy is successful at lowering the yields, with the exception of NIGST ones. Moreover, the beneficial effects are persistent, given that the responses converge to zero very slowly and remain significant for more than 4 months. Yet, the responses are very small, in the order of a handful of basis points at best.

In the low rates/high spreads state, the responses of IG yields to an expansionary policy are close to zero and never statistically significant. NIGST yields increase instead by 4 bps, but the effect is statistically significant only up to 2 weeks. On the contrary, NIGLT yields decrease by about 2 bps, but the effect is statistically significant only for the week subsequent to a monetary shock. This means that in all three regimes, the effects of a conventional monetary expansion are modest, often carry the wrong sign (given the likely desiderata of policymakers) and are predominantly not statistically significant.

These weak and regime-dependent (hence, time-varying) effects are however not completely surprising. For instance, since the seminal work by Bernanke and Mihov (1998), we know that a rate-based expansionary policy has mainly two effects: it increases real output and it raises the price level. Because we know from Ang and Piazzesi (2003) that macroeconomic factors are able to explain the majority of the variability of bond yields - in particular, a higher inflation triggers an increase in bond yields, especially short-term ones (but Evans and Marshall, 2007, extend this evidence to long-term bond yields) - an expansion of the monetary base is likely to increase inflation and, consequently, corporate yields. Moreover, our results emphasize that the response of corporate yields to a monetary shock depends on the economic regime. This is again coherent with the findings of Bernanke and Mihov (1998) who have tested their results on different sample periods and noticed that the responses of macro factors to a monetary shock are time-varying. In particular, in our framework, in the high rates/low spreads regime a monetary expansion triggers a reduction, albeit modest, of corporate yields instead of their increase. This is reasonable if one considers that an expansionary policy is likely to raise more concerns about future inflation when the rates are already low than when the level of interest rates is generally high. Finally, the crisis regime is the one that shows the most pronounced positive responses to a monetary expansion. This fact has several explanations. First of all, our data reveal that the crisis is the most volatile regime. Consequently, it is not surprising that this regime is the most reactive to any type of shocks. In addition, given that the monetary policy conducted by the Fed has in general a powerful signalling power, during a crisis it can generate negative expectations about 
the state of the real economy, as recently emphasized by the work of Christensen and Rudebusch (2012), Farmer (2012), and Krishnamurthy and Vissing-Jorgensen (2011).27 This may induce investors to demand a higher risk-premium, as will be examined momentarily. However, we note that this interpretation is immediately supported by the fact that the responses are more pronounced for NIG yields than for IG ones.

In Figure 11, the effects of an expansionary policy on credit spreads also vary according to the assumptions on the initial regime. However, conventional policies remain generally ineffective. In the high rates/low spreads state, the effects of an expansionary conventional policy are close to zero for both IG and NIG spreads. In particular, the responses of IG spreads are not statistically significant and do not even reach $1 \mathrm{bp}$; the responses of NIGs are statistically significant only in the week subsequent to the policy shock. NIGST spreads increase by about 3 bps, whereas the long-term ones decrease by about 2 bps. In contrast, the effects on corporate spreads are significant and persistent in the low rates/high spreads state. In this regime, IG and especially NIG spreads increase as a result of a shock. In particular, IGST spreads increase by $14 \mathrm{bps}$, while the long-term ones increase by 4 bps. The positive, counter-intuitive effects on NIG spreads are even more pronounced. For NIGST spreads, the effects peak (at approximately 46 bps) after a month and then start to slowly decay. NIGLT spreads, instead, increase by 14 bps. All the responses tend to remain significant for about 7-9 weeks with the exception of IGST bonds, which becomes statistically insignificant after just 2 weeks. These effects contradict the classical goals of the monetary authorities because an increment in credit spreads is a sign of an increase in the perceived risk of corporate bonds and is likely to hamper investments and hence real growth.

In the crisis state, the effects differ on the basis of whether we consider short or longterm bonds, irrespective of their IG or NIG nature: the response to an expansionary policy is not statistically significant for IGLT and even negative for NIGLT spreads. The latter decrease-which is the first instance consistent with objectives of an expansionary policy-by 18 bps, even though the effect levels off quickly and the response is statistically significant only for up to 3 weeks. In contrast, short-term spreads increase by about 6 bps for IG bonds and by 20 bps for the NIG ones. In both cases, the responses are significant for one month.

\footnotetext{
${ }^{27}$ Bauer and Rudebusch (2013) write that “(...) the Fed's unprecedented announcements of asset purchases with the goal of putting further downward pressure on yields might well have had an important signaling component, in the sense of conveying to market participants how bad the economic situation really was, and that extraordinarily easy monetary policy was going to remain in place for some time" (emphasis added).
} 
Also in this case, a literature exists that can be used to provide some foundations to our empirical results. For instance, $\mathrm{Wu}$ and Zhang (2008) have studied the effects that a shock to some macroeconomic factors, such as real output, inflation and market volatility, produce on corporate spreads. Their results suggest that a positive shock to inflation generates an increase in corporate spreads. These results are coherent with our findings, which show that an expansionary policy tends to increase spreads. Moreover, similarly to what happens to yields, the empirical responses were particularly pronounced in the crisis regime, especially for short-term spreads. This is consistent with the idea that corporate spreads not only incorporate the risk of default of the firm, but also a bond risk premium, similar to the equity risk premium. Gourio (2013) suggests that this risk premium compensates the investors for bearing "tail risk", i.e., the risk of low probability events with disastrous consequences, such as the collapse of the financial system.

\subsection{Effects of Quantitative Easing-Type Policies}

We analyze the effects on corporate yields and spreads of $\mathrm{QE}$, which we simulate as a negative, one-standard-deviation shock to the 10-year Treasury. In Figure 9, the effects of $\mathrm{QE}$ on corporate yields are remarkably different across IG and NIG portfolios. The responses of IG yields are not statistically significant in any of the regimes. On the contrary, the effects on NIG bonds depend on the regime and are particularly pronounced in times of crisis. In particular, in a crisis, QE leads to a reduction of about 28 bps in NIGST yields, which is consistent with typical objectives of QE. However, their responses are statistically significant only for two weeks after the implementation of the policy. In contrast, the policy increases NIGLT rates by about 40 bps. Nevertheless, the magnitude of this effect decreases quickly to fall below $1 \mathrm{bp}$ after one month. Although not very persistent, these effects contrast the objective of reducing long-term borrowing costs.

The responses to QE by NIGLT yields are not statistically significant both in the low rates/high spreads and in the high rates/low spreads regimes. In contrast, for NIGST yields, the response is significant and negative in the high rates/low spreads, whereas it is positive in the low rates/high spreads regime. In particular, in the high rates/low spreads regime the policy triggers a reduction of about $3 \mathrm{bps}$ in NIGST yields. However the response is significant only for the first 2 weeks. Instead, in the low rates/high spreads regime QE produces a persistent increase of about $12 \mathrm{bps}$ in NIGST yields which, as usual, are the most reactive among corporate rates. Very few of the responses to QE are significant. Noticeably, the most substantial effects are obtained in the regime of crisis, which is precisely when a QE policy is most likely to be implemented. However, even in this regime, the responses are significant only for NIG bonds. Moreover, the effects have 
opposite signs, negative for short-term yields and positive for long-term ones. This difference in the responses may be a result of the fact that long- and short-term bonds are likely to be held by investors with different preferences. However, the overall effect of QE is not the one desired by monetary authorities because it does not trigger a reduction of IG yields and even increases NIGST rates.

These results are in line with previous direct evidence on the effects that QE would have produced on the yields of assets different from those purchased directly by the Fed (i.e., the ones not directly involved in the purchase programs). The vast majority of the papers have concluded that QE was effective only in reducing the yields of the assets being purchased (e.g., Krishnamurthy and Vissing-Jorgensen, 2011). D'Amico and King (2013) reach a similar conclusion that government purchases of Treasuries have been able to reduce Treasury yields, but have had a minimal effect on corporates. ${ }^{28}$ Our conclusions are in line with the Ricardian equivalence-type work by Eggertsson and Woodford (2003) and Curdia and Woodford (2011) who have argued that when the central bank replaces private-sector holdings of long-term bond securities with money, it does not change the risk characteristics of the private sectors' portfolios as a whole because households ultimately bear any risk taken on by the government through the tax burden that they will be susceptible to bear in the future.

Similarly to the results for yields, many of the responses of IG spreads to the implementation of QE in Figure 12 are not statistically significant. In contrast, the effects of the policy on NIG spreads depend on the nature of the regime. In a state of crisis, the policy produces an increase of $22 \mathrm{bps}$ in NIGST spreads and of about $44 \mathrm{bps}$ in long-term ones. In both cases the responses tend to die away quickly and are statistically significant for less than 1 month. In the low rates/high spreads regime, QE produces a reduction of both NIGST and long-term spreads. In particular, the former decrease by about 33 bps, while the latter fall by approximately 15 bps. These responses tend to level off in 5-6 weeks and they remain statistically significant only for 3 weeks. Although they are not particularly persistent, these effects conform to the likely intended effects of the monetary policies. In contrast, in the high rates/low spreads regime the responses are by far less pronounced. In particular, the response of NIGLT spreads is not statistically

\footnotetext{
${ }^{28}$ Caution should be used when comparing our results to those that have already appeared in the literature because our study is not an ex-post evaluation of the Treasury purchases that have been conducted by the Fed during the recent financial crisis (i.e., LSAP1 and LSAP2). Instead, it is an attempt to assess if corporate bonds can be reasonably expected to be affected by a set of conventional and unconventional monetary policies. In this sense, a positive finding that the policies investigated in this study may affect yields and/or spreads would only represent a necessary condition for the effectiveness of the policy interventions. However, our results confirm the idea that QE may not be particularly efficient at lowering corporate yields.
} 
significant. NIGST spreads, instead, are subject to a decrease of about $7 \mathrm{bps}$, but the effect is statistically significant only for up to two weeks.

All in all, the effects of QE on the spreads are similar to the ones that have been observed for the yields. Indeed, many of the responses are not significant, especially for IG bonds. Furthermore, in the crisis regime QE produces an increase of both short- and long-term spreads. These results are compatible with the fact that QE implies the creation of monetary base, which increases inflation (see Bernanke and Mihov, 1998). As explained in Sections 3 and 4.4, a positive shock to expected inflation may then trigger an increase in corporate yields and spreads, according to Krishnamurthy and Vissing-Jorgensen's (2011) inflation expectations channel.

\subsection{Effects of Operation "Twist"-Type Policies}

Finally, we analyze the effects on corporate yields and spreads of OT, which is simulated as a one-standard deviation negative shock to the 10-year Treasury yield accompanied by a positive one-standard-deviation shock to the 1-month T-bill rate. Similar to the other policies, the effects of OT in Figure 10 depend on the state that prevails when the policy is implemented. In the state of crisis the IRFs are significant and negative for all corporate yields, with the only exception of NIGLT rates. The latter are subject to an increase of about 31 bps. However, the effects turn negative after two weeks and become statistically insignificant. On the contrary, OT reduces IGST yields by about $10 \mathrm{bps}$, IGLT yields by about 11 bps and NIGST yields by about 79 bps. While the responses of IG yields decrease quickly and become statistically insignificant after 3 weeks, the reduction in NIGST yields is particularly persistent. Indeed, although the impact decreases over time, it remains negative and statistically significant for more than 2 months. Thus, these results show that OT may be quite effective in lowering corporate yields, in line with the objectives of the Fed. This occurs exactly during a crisis period, which fits the best interests of policymakers. In the low rates/high spreads state, the responses of IG yields to OT are statistically insignificant, whereas the policy slightly increases NIGST and long-term yields by about 7 bps and 5 bps, respectively. However, these effects level off quickly and the responses become insignificant after less than 1 month. In the high rates/low spreads regime, OT reduces corporate yields, with the exception of NIGST yields, which experience a drop of about $6 \mathrm{bps}$ in the period that follows a policy shock. Nevertheless, the effects turn positive after a month and the responses become statistically insignificant after 3 weeks. ${ }^{29}$

\footnotetext{
${ }^{29}$ IGST and IGLT yields, instead, increase by about 2 bps and $1 \mathrm{bp}$, respectively. Besides being
} small, these effects are not particularly persistent and the responses become statistically 
OT is a policy that consists in the contemporaneous purchase of long-term Treasuries and the sale of short-term ones. Thus, this policy is able to reduce the slope of the riskless yield curve without increasing the monetary base. Our results show that in times of crisis, the policy is able to lower yields for a majority of corporates, with the exception of NIGLT yields. These results may be interpreted as a confirmation of the role of expected inflation in driving corporate rates. In fact, both $\mathrm{QE}$ and conventional expansionary monetary policies, which imply the expansion of the monetary base and thus are likely to increase inflation (see Bernanke and Mihov, 1998), trigger an increase in corporate yields and spreads. On the contrary, OT, which does not imply the expansion of the monetary base, may be considered the most effective policy in reducing corporate yields and spreads.

The effects of OT on corporate spreads in Figure 13 are in general more pronounced for NIG bonds. In the crisis state, for example, the responses of IG spreads to the implementation of the policy are statistically insignificant. NIGST and NIGLT spreads, instead, increase by about 10 bps and 63 bps, respectively. For NIGST spreads the response is significant only over the week following a shock. For NIGLT spreads the response is statistically significant up to 3 weeks. In the low rates/high spreads regime, OT produces negative responses for all spreads except IGLT ones. In fact, for the latter the response is not statistically significant. Instead, IGST spreads decrease by about $10 \mathrm{bps}$. The effects are more pronounced for short- and long-term NIG bonds: indeed, their spreads drop by about 70 and 30 bps, respectively. Although decreasing, their responses remain statistically significant for more than 1 month after the implementation of the policy, which represents a considerable effect. In contrast to the crisis regime, in this state the overall effects of OT are in line with the objectives of the monetary authorities. Finally, in the high rates/low spreads state the responses of corporate spreads to the policy are in general not statistically significant. The only exception concerns NIGLT spreads, which slightly increase (3 bps). However, the effects are statistically significant only during the first week after the implementation of the policy.

Thus, while in the low rates/high spreads regime the relationship between corporate spreads and Treasury yields is generally positive (i.e., a reduction in the slope is associated with a reduction in the spreads), in the crisis regime this relationship becomes negative, in line with the findings of Duffee (1998). This is coherent with the welldocumented idea that the slope of the Treasury yield curve is a leading indicator of the business cycle. In particular, a reduction of the slope is interpreted as a signal of an imminent recession. Clearly, this is especially true in a crisis regime when a recession is

insignificant after less than 1 month. Finally, the policy produces an increase in NIGLT yields in the order of $5 \mathrm{bps}$, which lasts for about a month. 
impending. Consequently, a negative shock to the slope is likely to increase the risk premium component of the spreads, as suggested by Gourio (2013). Thus, in the crisis regime, OT can be expected to lower the yields, as it is a non-inflationary policy, but it increases the spreads, because of the signals that it sends to the market about the conditions of the economy.

\subsection{Robustness checks}

We provide a set of robustness checks for our MSVARs similar to the robustness exercises described in Section 3.4. In particular, we re-estimate the $\operatorname{MSIH}(3,1)$ model for both the yields and the spreads with the Treasury yield factors-i.e., level, slope and curvature-in place of the Treasury yield series. Our robustness checks confirm most of our reported results. In particular, this exercise allows us to verify that our interpretation of the regimes holds in this alternative framework. This matters because incorrect definitions of the states would affect the interpretation of the economic consequences of different types of monetary policies. ${ }^{30}$ Appendix D shows that OT, modelled as a change in the slope factor, causes large, persistent, and statistically significant declines in yields, especially in short-term corporate rates, both NIGST and IGST; the effects are weaker and their sign shifts over time in the case of long-term corporate rates. The bottom panel of the appendix shows that roughly two-thirds of the effects derive from a decline in risk premia. However, these effects manifest themselves only in the crisis regime and not in the two remaining states, similarly to the evidence uncovered above.

\section{Conclusions}

We have investigated the effects on corporate spreads and yields of three different types of policies: a conventional monetary expansion, quantitative easing, and operation twist. We simulated the three policies through shocks to the Treasury yields and studied the IRFs of corporate yields and spreads. This approach is different from the one that has been adopted by many previous studies (e.g., Gagnon et al., 2010; Hamilton and Wu, 2010) that have tried to measure the effects of conventional and unconventional monetary policies during the recent financial crisis using ex-post data on resulting changes in yields and economic performance, mostly through event studies. Indeed, our goal is not to provide an ex-post evaluation of the policies, but rather to understand what are the general time series responses one would have expected on the basis of relatively long time series of data at the time the interventions were implemented.

\footnotetext{
${ }^{30}$ Complete results of all robustness checks are available from the author(s) upon request.
} 
We employ two different econometric frameworks in our analysis: a single-state VAR model and a three-state MS VAR model. Our results indicate that a single-state model is not adequate to capture the dynamics of the data. First, the null hypothesis of only one regime was rejected. Second, the analyses of the MS-implied IRFs demonstrated that the effects of the policies vary with the economic regime that prevails at the moment of a monetary policy impulse. Ignoring the presence of different regimes entails the risk of miscalculating the magnitude, and occasionally even the sign, of the impulse response functions. Therefore, relying on a single-state model would possibly induce the monetary authorities to form misleading expectations about the effects of their policies on corporate securities and hence on the decisions and investment behavior by firms.

Our results show that the responses of corporate bonds to the simulated policies are statistically significant and large only in the crisis state. Considering that this regime is the most relevant for the purpose of our analysis because we focus on the policies that the Fed carried out during the 2008-2009 financial turmoil and ensuing recession, it is worthwhile to summarize here the results and their main implications. In the crisis regime a conventional monetary policy tends to increase both corporate yields and spreads. This can be interpreted as a consequence not only of the inflation that this policy may be expected to trigger, but also of the risk premium that the investors demand to bear any "tail risks" (see Gourio, 2013). Quantitative easing, which is an inflationary monetary policy, is able to lower NIGLT yields, but does not produce any relevant effect on IG yields and it increases NIGST yields. As for the spreads, quantitative easing tends to increase them as well. Finally, operation twist, which is instead a non-inflationary monetary policy, is able to decrease the yields, but it rather increases the spreads. Again, this can be interpreted as a consequence of a risk premium component. Thus, during a crisis, none of the policies can be expected to lower corporate bond spreads. This is probably due to the fact that the signals conveyed by these policies about the business cycle are more likely to increase the bond risk-premium rather than to decrease it. This evidence contradicts the notion that unconventional monetary policies are most effective at reducing risk premia (see, e.g., Gagnon et al., 2011) and is consistent with the evidence in Christensen and Rudebusch (2012) that declines in premia played a relatively modest role in the impact of QE on U.S. yields. Even though our reduced-form models are unsuitable for disentangling the portfolio balance from the signalling transmission channels, this result echoes Bauer and Rudebusch's (2013) conclusion that although much of the policy debate has insisted on the portfolio effects of unconventional policies, it may have been the signalling of lower future rates that played the most important role. 
However, operation twist can be expected to lower yields, especially for NIG bonds. This echoes Swanson's (2011) findings that the earlier historical OT episode in the U.S. led to similarly sized, hence effective, announcement effects on Treasury yields and Hamilton and Wu's (2012) positive results on the effectiveness of OT. Equivalently, our paper can be interpreted as providing evidence on the ex-ante effectiveness of an aggregate duration channel of unconventional policy pursued through OT. If investors dislike interest rate (duration) risk, when the central bank purchases long-duration assets it reduces the aggregate amount of duration risk that remains in the market and needs to be borne by the private sector. As a result, the compensation required by investors to hold all remaining bonds carrying duration risk falls, putting downward pressure on yields.

\section{References}

Ang, A., and M. Piazzesi, 2003, "A no-arbitrage vector autoregression of term structure dynamics with macroeconomic and latent variables," Journal of Monetary Economics, 50(4), 745-787.

Ang, A., and A., Timmermann, 2011, “Regime changes and financial markets,” NBER working paper No. 17182.

Bansal, R., and H., Zhou, 2002, "Term structure of interest rates with regime shifts," Journal of Finance, 57(5), 1997-2043.

Bauer, M. D., and G. D. Rudebusch., 2013, "The signaling channel for Federal Reserve bond purchases," Federal Reserve Bank of San Francisco working paper No. 21.

Bekaert, G., M. Hoerova and M. Lo Duca, 2013, "Risk, Uncertainty and Monetary Policy," Journal of Monetary Economics, 60(7), 771-788.

Bernanke, B.S., and I. Mihov, 1998, "Measuring monetary policy," Quarterly Journal of Economics, 113(3), 869-902.

Bessembinder, H., K.M. Kahle, W.F. Maxwell and D. Xu, 2009, "Measuring abnormal bond performance," Review of Financial Studies, 22(10), 4219-4258.

Bowdler, C., and A. Radia, 2012, "Unconventional monetary policy: the assessment," Oxford Review of Economic Policy, 28(4), 603-621.

Chen, H., V., Curdia, and A., Ferrero, 2012, "The macroeconomic effects of large-scale asset purchase programs," Economic Journal, 122(564), F289-F315.

Christensen, J.H.E., and G.D. Rudebusch, 2012, "The response of government yields to central bank purchases of long-term bonds," Economic Journal, 122(564), F385-F414.

Cronin, D., 2013, "The interaction between money and asset markets: A spillover index approach," Journal of Macroeconomics, forthcoming.

Cúrdia, V., and M. Woodford, 2011, "The central-bank balance sheet as an instrument of monetary policy," Journal of Monetary Economics, 58(1), 54-79.

D'Amico, S., and T.B. King, 2013, "Flow and stock effects of large-scale treasury purchases: Evidence on the importance of local supply," Journal of Financial Economics, 108(2), 425-448.

Dick-Nielsen, J., 2009, “Liquidity Biases in TRACE,” Journal of Fixed Income, 19(2), 43-55. 
Duffee, G.R., 1998, "The relation between treasury yields and corporate bond yield spreads," Journal of Finance, 53(6), 2225-2241.

Eggertsson, G., and M. Woodford, 2003, "The zero bound on interest rates and optimal monetary policy," Brookings Papers on Economic Activity, 1, 139-233.

Enders, W., 1995, Applied econometric time series, New York: Wiley.

Evans, C.L., and D.A., Marshall, 2007, "Economic determinants of the nominal treasury yield curve," Journal of Monetary Economics, 54(7), 1986-2003.

Farmer, R.E.A., 2012, "The effect of conventional and unconventional monetary policy rules on inflation expectations: theory and evidence," Oxford Review of Economic Policy, 28(4), 622639.

Gagnon, J., M. Raskin, J. Remache and B. Sack, 2011, "The financial market effects of the Federal Reserve's large-scale asset purchases," International Journal of Central Banking, 7(1), 3-43.

Gilchrist, S. and E., Zakrajšek, 2013, "The impact of the Federal Reserve's Large-Scale Asset Purchase programs on corporate credit risk," NBER working paper No. 19337.

Goldstein, R., N. Ju and H. Leland, 2001, “An EBIT-based model of dynamic capital structure," Journal of Business, 74(4), 483-512.

Goodfriend, M., 2011, "Central banking in the credit turmoil: An assessment of Federal Reserve practice," Journal of Monetary Economics, 58(1), 1-12.

Gourio, F., 2013, "Credit risk and disaster risk," American Economic Journal: Macroeconomics, $5(3), 1-34$

Greenwood, R., and D. Vayanos, 2008, "Bond supply and excess bond returns," NBER working paper 13806.

Guidolin, M., and A. Timmermann, 2009, "Forecasts of U.S. short-term interest rates: A flexible forecast combination approach", Journal of Econometrics, 150(22), 297-311.

Guidolin, M., 2012, "Markov switching models in empirical finance," IGIER Bocconi University working paper No. 415.

Hamilton, J.D., 1993, "Estimation, inference, and forecasting of time series subject to changes in regime," in G. Maddala, C. Rao and H. Vinod, eds., Handbook of Statistics, vol. 11, Amsterdam: North Holland, 231-260.

Hamilton, J.D., 1994, Time Series Analysis, Princeton: Princeton University Press.

Hamilton, J.D., and J.C. Wu, 2012, "The effectiveness of alternative monetary policy tools in a zero lower bound environment," Journal of Money, Credit and Banking, 44(S1), 3-46.

Hayashi, F., and J. Koeda, 2013, "A regime-switching SVAR analysis of quantitative easing," working paper, Hitotsubashi University and University of Tokyo.

Joyce, M., A. Lasaosa, I. Stevens and M. Tong, 2011, "The financial market impact of quantitative easing," International Journal of Central Banking, 7(3), 113-161.

Joyce, M., D. Miles, A. Scott and D. Vayanos, 2012, "Quantitative easing and unconventional monetary policy - an introduction," Economic Journal, 122(564). F271-F288.

Joutz, F., S.A. Mansi and W.F. Maxwell, 2001, "The dynamics of corporate credit spreads," George Washington University working paper. 
Kapetanios, G., H. Mumtaz, I. Stevens and K. Theodoridis, 2012, “Assessing the economy-wide effects of quantitative easing," Economic Journal, 122(564), F316-F347.

Kilian, L, 1998, "Small-sample confidence intervals for impulse response functions," Review of Economics and Statistics, 80(2), 218-230.

Koop, G., M.H. Pesaran and S.M. Potter, 1996, "Impulse response analysis in nonlinear multivariate models," Journal of Econometrics, 74(1), 119-147.

Krishnamurthy, A., and A. Vissing-Jorgensen, 2011, "The effects of quantitative easing on interest rates: Channels and implications for policy," Brookings Papers on Economic Activity, 2, 215-287.

Krolzig, H.-M., 1997, Markov-switching vector autoregressions: Modeling, statistical inference, and application to business cycle analysis, Berlin: Springer-Verlag.

Lin, M., and J.-C. Curtillet, 2007, "Another look at the relation between credit spreads and interest rates," Journal of Fixed Income, 17(1), 59-71.

Littermann, R.B., and J. Scheinkman, 1991, “Common factors affecting bond returns," Journal of Fixed Income, 1(1), 54-61.

Longstaff, F.A., 2010, "The subprime credit crisis and contagion in financial markets," Journal of Financial Economics, 97(3), 436-450.

Longstaff, F.A., and E.S. Schwartz, 1995, "A simple approach to valuing risky fixed and floating rate debt," Journal of Finance, 50(3), 789-821.

Lütkepohl, H., 1991, Introduction to multiple time series analysis, New York: Springer.

Martin, C., and C. Milas, 2012, "Quantitative easing: A sceptical survey," Oxford Review of Economic Policy, 28(4), 750-764.

Neal, R., D. Rolph and C. Morris, 2000, “Interest rates and credit spread dynamics," Indiana University working paper.

Potter, S.M., 2000, “Nonlinear impulse response functions," Journal of Economic Dynamics and Control, 24(10), 1425-1446.

Sarig, O., and A. Warga, 1989, "Some empirical estimates of the risk structure of interest rates," Journal of Finance, 44(5), 1351-1360.

Swanson, E.T., 2011, "Let's twist again: A high-frequency event-study analysis of operation twist and its implications for QE2," Brookings Papers on Economic Activity, 1, 151-207.

Vayanos, D., J.-L. Vila, 2009, "A preferred-habitat model of the term structure of interest rates," NBER working paper No. 15487.

Williams, N., 2012, "Monetary policy under financial uncertainty," Journal of Monetary Economics, 59(5), 449-465.

Wright, J.H., 2012, "What does monetary policy do to long-term interest rates at the zero lower bound?", Economic Journal, 122(564), F447-F466.

Wu, L, and F.X. Zhang, 2008, "A no-arbitrage analysis of macroeconomic determinants of the credit spread term structure," Management Science, 54(6), 1160-1175. 


\section{Table 1: Summary statistics for corporate yields}

Panel A reports the main statistics for corporate yield series over the sample October 8, 2004 December 28, 2012. The data are expressed in terms of annualized percentage nominal yields. Based on the Jarque-Bera test statistic, the null hypothesis of a normal distribution is rejected for all portfolios at all conventional levels of significance. Panel B reports correlations among the four portfolios.

\section{Panel A}

\begin{tabular}{ccccccccc}
\hline & Mean & & & & \multicolumn{2}{c}{ Std. } & & \multicolumn{2}{c}{ Jarque- } \\
& & Median & Maximum & Minimum & Dev. & Skewness & Kurtosis & Bera \\
\hline Investment Grade ST & 3.792 & 4.134 & 11.190 & 1.196 & 1.790 & 0.415 & 3.057 & 12.386 \\
Investment Grade LT & 5.343 & 5.188 & 8.962 & 3.287 & 1.039 & 0.910 & 4.591 & 104.680 \\
Non-Investment Grade ST & 10.636 & 8.349 & 42.434 & 4.213 & 7.171 & 2.626 & 9.734 & 1306.53 \\
Non-Investment Grade & 9.066 & 7.945 & 35.615 & 4.839 & 3.789 & 2.715 & 13.009 & 2323.0 \\
LT & & & & & & & & \\
\hline
\end{tabular}

Panel B

\begin{tabular}{ccccc}
\hline Correlation & $\begin{array}{c}\text { Investment Grade } \\
\text { ST }\end{array}$ & $\begin{array}{c}\text { Investment Grade } \\
\text { LT }\end{array}$ & $\begin{array}{c}\text { Non-Investment } \\
\text { Grade ST }\end{array}$ & $\begin{array}{c}\text { Non-Investment } \\
\text { Grade LT }\end{array}$ \\
\hline Investment Grade ST & 1.000 & & & \\
Investment Grade LT & 0.863 & 1.000 & & \\
Non-Investment Grade ST & 0.480 & 0.759 & 1.000 & 1.000 \\
Non-Investment Grade LT & 0.275 & 0.603 & 0.876 & \\
\hline
\end{tabular}

\section{Table 2: Summary statistics for corporate spreads}

Panel A reports the main statistics for corporate spreads. The data are expressed in terms of annualized percentage nominal yields. Based on the Jarque-Bera test statistic, the null hypothesis of a normal distribution is rejected for all corporate spreads at all conventional levels of significance. Panel B reports correlations for corporate spreads.

\section{Panel A}

\begin{tabular}{|c|c|c|c|c|c|c|c|c|}
\hline & $\overline{\mathrm{N}}$ & Median & & & & & & \\
\hline Investment Grade ST & 1.530 & 1.189 & 9.363 & 0.308 & 1.414 & 2.417 & 9.834 & 1255.5 \\
\hline Investment Grade LT & 2.105 & 2.103 & 6.392 & 0.735 & 1.212 & 1.198 & 4.347 & 135.34 \\
\hline Non-Investment Grade ST & 8.349 & 6.338 & 41.182 & 1.393 & 7.705 & 2.387 & 8.634 & 977.15 \\
\hline Non-Investment Grade LT & 5.818 & 5.077 & 33.698 & 1.690 & 4.255 & 2.194 & 10.278 & 1294.0 \\
\hline
\end{tabular}

\section{Panel B}

\begin{tabular}{ccccc}
\hline Correlation & $\begin{array}{c}\text { Investment Grade } \\
\text { ST }\end{array}$ & $\begin{array}{c}\text { Investment Grade } \\
\text { LT }\end{array}$ & $\begin{array}{c}\text { Non-Investment } \\
\text { Grade ST }\end{array}$ & $\begin{array}{c}\text { Non-Investment } \\
\text { Grade LT }\end{array}$ \\
\hline Investment Grade ST & 1.000 & & & \\
Investment Grade LT & 0.909 & 1.000 & & \\
Non-Investment Grade ST & 0.876 & 0.873 & 1.000 & \\
Non-Investment Grade LT & 0.812 & 0.866 & 0.895 & 1.000 \\
\hline
\end{tabular}




\section{Table 3: Principal component analysis}

The table reports the principal component decomposition of the Treasury yield curve. It shows the eigenvalues associated with each principal component and the portion of total variance accounted for by each component.

\begin{tabular}{ccc}
\hline $\begin{array}{c}\text { Principal } \\
\text { Component }\end{array}$ & Eigenvalues & $\begin{array}{c}\text { Portion of Explained } \\
\text { Variance }\end{array}$ \\
\hline Level & 8.567 & $95.19 \%$ \\
Slope & 0.400 & $4.44 \%$ \\
Curvature & 0.026 & $0.29 \%$ \\
PC4 & 0.005 & $0.06 \%$ \\
PC5 & 0.001 & $0.01 \%$ \\
PC6 & 0.001 & $0.01 \%$ \\
PC7 & 0.000 & $0.00 \%$ \\
PC8 & 0.000 & $0.00 \%$ \\
PC9 & 0.000 & $0.00 \%$ \\
\hline
\end{tabular}

\section{Table 4: Summary statistics for Treasury yields}

Panel A reports the main statistics for constant-maturity Treasury yields. The data are expressed in terms of annualized percentage nominal yields. Based on the Jarque-Bera test statistic, the null hypothesis of a normal distribution is rejected for all Treasury yields at all conventional levels of significance. Panel B reports correlations among the different Treasury yields.

\section{Panel A}

\begin{tabular}{ccccccccc}
\hline & Mean & Median & Maximum & Minimum & Std. Dev. & Skewness & Kurtosis & Jarque-Bera \\
\hline 1 m Treasury yield & 1.732 & 0.230 & 5.250 & 0.000 & 1.926 & 0.606 & 1.740 & 54.784 \\
1 y Treasury yield & 2.030 & 1.240 & 5.270 & 0.100 & 1.923 & 0.453 & 1.540 & 52.875 \\
5 y Treasury yield & 2.836 & 2.640 & 5.180 & 0.590 & 1.399 & 0.010 & 1.695 & 30.517 \\
10 y Treasury yield & 3.584 & 3.720 & 5.220 & 1.470 & 1.002 & -0.473 & 2.193 & 27.708 \\
\hline
\end{tabular}

\section{Panel B}

\begin{tabular}{ccccc}
\hline Correlation & 1 m Treasury yield & 1 y Treasury yield & 5 y Treasury yield & 10 y Treasury yield \\
\hline 1 m Treasury yield & 1.000 & & & \\
1 y Treasury yield & 0.989 & 1.000 & & \\
5 y Treasury yield & 0.916 & 0.947 & 1.000 & \\
10 y Treasury yield & 0.822 & 0.858 & 0.973 & 1.000 \\
\hline
\end{tabular}




\section{Table 5: Summary statistics for Treasury yield curve factors}

Panel A reports the main statistics for level, slope and curvature - the three factors that summarize the Treasury term structure. The factors are expressed in terms of annualized nominal percentage yields. Based on the Jarque-Bera test statistic, the null hypothesis of a normal distribution is rejected for all fators at all conventional levels of significance. Panel B reports correlations for the three factors.

Panel A

\begin{tabular}{ccccccccc}
\hline & Mean & Median & Maximum & Minimum & Std. Dev. & Skewness & Kurtosis & Jarque-Bera \\
\hline Level & 7.195 & 4.804 & 15.441 & 1.322 & 4.864 & 0.390 & 1.573 & 47.357 \\
Slope & 1.931 & 1.995 & 4.268 & -0.565 & 1.329 & -0.091 & 1.931 & 21.057 \\
Curvature & 0.168 & 0.214 & 1.013 & -0.699 & 0.314 & -0.241 & 2.410 & 10.406 \\
\hline
\end{tabular}

Panel B

\begin{tabular}{cccc}
\hline Correlation & Level & Slope & Curvature \\
\hline Level & 1.000 & & \\
Slope & -0.761 & 1.000 & \\
Curvature & -0.244 & -0.121 & 1.000 \\
\hline
\end{tabular}


Table 6: Estimation results: MSIH(3,1)-yields

\begin{tabular}{|c|c|c|c|c|c|c|c|c|}
\hline & $\begin{array}{c}\text { Investment } \\
\text { Grade ST }\end{array}$ & $\begin{array}{c}\text { Investment } \\
\text { Grade LT }\end{array}$ & $\begin{array}{c}\text { Non-Investment } \\
\text { Grade ST }\end{array}$ & $\begin{array}{c}\text { Non-Investment } \\
\text { Grade LT }\end{array}$ & $\begin{array}{c}1 \mathrm{~m} \text { Treasury } \\
\text { yield }\end{array}$ & $\begin{array}{l}1 \text { y Treasury } \\
\text { yield }\end{array}$ & $\begin{array}{c}5 \text { y Treasury } \\
\text { yield }\end{array}$ & $\begin{array}{c}10 \text { y Treasury } \\
\text { yield }\end{array}$ \\
\hline \multicolumn{9}{|l|}{ 1. Intercept term } \\
\hline Regime 1 & $-0.365^{* * *}$ & $0.152 * *$ & $0.376^{* * *}$ & $0.975^{* * *}$ & $-0.070^{* * *}$ & -0.014 & $-0.101 *$ & -0.069 \\
\hline (Low rates/High spreads) & $(0.000)$ & $(0.049)$ & $(0.008)$ & $(0.000)$ & $(0.005)$ & $(0.489)$ & $(0.069)$ & $(0.229)$ \\
\hline Regime 2 & 0.193 & $0.227^{* *}$ & $1.166^{* * *}$ & $1.892^{* * *}$ & $-0.148^{* * *}$ & $-0.073^{* *}$ & $-0.198^{* * *}$ & $-0.140 * *$ \\
\hline (High rates/Low spreads) & $(0.147)$ & $(0.013)$ & $(0.000)$ & $(0.000)$ & $(0.006)$ & $(0.027)$ & $(0.002)$ & $(0.032)$ \\
\hline Regime 3 & 0.035 & $0.196 * * *$ & -0.003 & 0.017 & $-0.103^{* *}$ & 0.015 & -0.077 & -0.057 \\
\hline (Crisis) & $(0.689)$ & $(0.010)$ & $(0.986)$ & $(0.854)$ & $(0.02)$ & $(0.564)$ & $(0.187)$ & $(0.328)$ \\
\hline \multicolumn{9}{|l|}{ 2. VAR(1) Matrix } \\
\hline Investment Grade ST & $0.693^{* * *}$ & $0.066^{* *}$ & 0.270 & $0.201^{* *}$ & $-0.056^{* * *}$ & -0.003 & 0.005 & -0.008 \\
\hline$(\mathrm{t}-1)$ & $(0.000)$ & $(0.016)$ & $(0.125)$ & $(0.04)$ & $(0.000)$ & $(0.729)$ & $(0.763)$ & $(0.631)$ \\
\hline Investment Grade LT & $0.228^{* * *}$ & $0.87 * * *$ & 0.092 & 0.127 & $0.039 * * *$ & 0.006 & $0.043^{* *}$ & $0.068^{* * *}$ \\
\hline$(\mathrm{t}-1)$ & $(0.000)$ & $(0.000)$ & $(0.716)$ & $(0.352)$ & $(0.003)$ & $(0.545)$ & $(0.047)$ & $(0.002)$ \\
\hline Non-Investment Grade ST & $0.009^{* * *}$ & 0.004 & $0.823^{* * *}$ & $0.062^{* * *}$ & 0.000 & -0.002 & $-0.007^{* * *}$ & $-0.009 * * *$ \\
\hline$(t-1)$ & $(0.004)$ & $(0.173)$ & $(0.000)$ & $(0.000)$ & $(0.767)$ & $(0.015)$ & $(0.001)$ & $(0.000)$ \\
\hline$(\mathrm{t}-1)$ & $(0.110)$ & $(0.815)$ & $(0.005)$ & $(0.000)$ & $(0.31)$ & $(0.483)$ & $(0.108)$ & $(0.100)$ \\
\hline $1 \mathrm{~m}$ Treasury yield & 0.053 & 0.032 & -0.244 & $0.193^{* *}$ & $0.785^{* * *}$ & $-0.053^{* * *}$ & -0.035 & -0.008 \\
\hline$(\mathrm{t}-1)$ & $(0.202)$ & $(0.236)$ & $(0.169)$ & $(0.045)$ & $(0.000)$ & $(0.000)$ & $(0.141)$ & $(0.726)$ \\
\hline 1 y Treasury yield & 0.042 & -0.028 & 0.067 & $-0.357 *$ & $0.278^{* * *}$ & $1.058^{* * *}$ & 0.043 & -0.008 \\
\hline$(t-1)$ & $(0.483)$ & $(0.528)$ & $(0.846)$ & $(0.074)$ & $(0.000)$ & $(0.000)$ & $(0.252)$ & $(0.813)$ \\
\hline 5 y Treasury yield & 0.004 & -0.161 & 0.701 & -0.325 & -0.033 & -0.02 & $0.981^{* * *}$ & 0.090 \\
\hline$(\mathrm{t}-1)$ & $(0.954)$ & $(0.023)$ & $(0.288)$ & $(0.379)$ & $(0.108)$ & $(0.232)$ & $(0.000)$ & $(0.112)$ \\
\hline 10 y Treasury yield & -0.039 & $0.191^{* * *}$ & -0.843 & $0.605^{*}$ & -0.006 & 0.007 & -0.029 & $0.872^{* * *}$ \\
\hline$(\mathrm{t}-1)$ & $(0.577)$ & $(0.005)$ & $(0.164)$ & $(0.068)$ & $(0.761)$ & $(0.648)$ & $(0.548)$ & $(0.000)$ \\
\hline$R$-squared & 0.964 & 0.976 & 0.932 & 0.881 & 0.995 & 0.995 & 0.999 & 0.990 \\
\hline 3.Unconditional mean & & & & & & & & \\
\hline Regime 1 (Low rates/High spreads) & 1.349 & 3.585 & 6.866 & 7.106 & 0.183 & 0.220 & 0.562 & 1.546 \\
\hline Regime 2 (High rates/Low spreads) & 5.456 & 6.024 & 8.992 & 7.773 & 4.388 & 4.644 & 4.840 & 5.047 \\
\hline Regime 3 (Crisis) & 4.453 & 6.861 & 29.016 & 17.022 & -5.343 & -3.793 & -0.352 & 1.489 \\
\hline
\end{tabular}




\section{Table 6 (Continued)}

\begin{tabular}{|c|c|c|c|c|c|c|c|c|}
\hline & $\begin{array}{l}\text { Investment } \\
\text { Grade ST }\end{array}$ & $\begin{array}{c}\text { Investment } \\
\text { Grade LT }\end{array}$ & $\begin{array}{c}\text { Non-Investment } \\
\text { Grade ST }\end{array}$ & $\begin{array}{c}\text { Non-Investment } \\
\text { Grade LT }\end{array}$ & $\begin{array}{l}1 \text { m Treasury } \\
\text { yield }\end{array}$ & $\begin{array}{l}1 \text { y Treasury } \\
\text { yield }\end{array}$ & $\begin{array}{l}5 \text { y Treasury } \\
\text { yield }\end{array}$ & $\begin{array}{c}10 \text { y Treasury } \\
\text { yield }\end{array}$ \\
\hline $\begin{array}{l}\text { 4. Correlations/Volatilities } \\
\text { Regime } 1\end{array}$ & & & & & & & & \\
\hline Investment Grade ST & 0.095 & & & & & & & \\
\hline Investment Grade LT & 0.519 & 0.103 & & & & & & \\
\hline Non-Investment Grade ST & 0.060 & 0.115 & 1.586 & & & & & \\
\hline Non-Investment Grade LT & -0.114 & 0.019 & 0.150 & 1.065 & & & & \\
\hline $1 \mathrm{~m}$ Treasury yield & -0.062 & -0.044 & -0.037 & 0.059 & 0.023 & & & \\
\hline 1 y Treasury yield & 0.029 & -0.019 & 0.019 & -0.075 & 0.249 & 0.021 & & \\
\hline 5 y Treasury yield & -0.059 & -0.083 & -0.050 & -0.083 & -0.115 & 0.627 & 0.095 & \\
\hline 10 y Treasury yield & -0.103 & -0.071 & -0.051 & -0.070 & -0.087 & 0.507 & 0.910 & 0.101 \\
\hline Regime 2 & & & & & & & & \\
\hline Investment Grade ST & 0.144 & & & & & & & \\
\hline Investment Grade LT & 0.465 & 0.083 & & & & & & \\
\hline Non-Investment Grade LT & 0.199 & 0.150 & 0.206 & 0.270 & & & & \\
\hline $1 \mathrm{~m}$ Treasury yield & 0.179 & 0.238 & -0.029 & 0.075 & 0.123 & & & \\
\hline 1 y Treasury yield & 0.102 & 0.030 & 0.022 & -0.086 & 0.199 & 0.059 & & \\
\hline 5 y Treasury yield & 0.084 & 0.039 & 0.095 & -0.103 & 0.003 & 0.847 & 0.087 & \\
\hline $\begin{array}{c}10 \text { y Treasury yield } \\
\text { Regime } 3\end{array}$ & 0.061 & 0.041 & 0.088 & -0.121 & -0.061 & 0.746 & 0.954 & 0.076 \\
\hline Investment Grade ST & 0.927 & & & & & & & \\
\hline Investment Grade LT & 0.632 & 0.390 & & & & & & \\
\hline Non-Investment Grade ST & 0.557 & 0.547 & 4.374 & & & & & \\
\hline Non-Investment Grade LT & 0.315 & 0.111 & 0.421 & 3.118 & & & & \\
\hline $1 \mathrm{~m}$ Treasury yield & -0.216 & -0.106 & -0.107 & -0.023 & 0.327 & & & \\
\hline 1 y Treasury yield & -0.122 & 0.079 & -0.006 & -0.091 & 0.637 & 0.180 & & \\
\hline 5 y Treasury yield & -0.139 & 0.146 & 0.006 & -0.263 & 0.229 & 0.583 & 0.163 & \\
\hline 10 y Treasury yield & -0.115 & 0.155 & 0.113 & -0.247 & 0.100 & 0.342 & 0.865 & 0.155 \\
\hline 5.Transition Matrix & \multicolumn{2}{|c|}{ Regime 1} & \multicolumn{2}{|c|}{ Regime 2} & \multicolumn{2}{|c|}{ Regime 3} & & \\
\hline Regime 3 (Crisis) & \multicolumn{2}{|c|}{0.06} & \multicolumn{2}{|c|}{0.11} & \multicolumn{2}{|c|}{0.83} & & \\
\hline
\end{tabular}

${ }^{*}$ significat at $10 \%$ level, ${ }^{* *}$ significant at $5 \%$ level, ${ }^{* * *}$ significant at $1 \%$ level 
Table 7: Estimation results: MSIH(3,1)-spreads

\begin{tabular}{|c|c|c|c|c|c|c|c|c|}
\hline & $\begin{array}{c}\text { Investment } \\
\text { Grade ST }\end{array}$ & $\begin{array}{c}\text { Investment } \\
\text { Grade LT }\end{array}$ & $\begin{array}{c}\text { Non-Investment } \\
\text { Grade ST }\end{array}$ & $\begin{array}{c}\text { Non-Investment } \\
\text { Grade LT }\end{array}$ & $\begin{array}{c}1 \text { m Treasury } \\
\text { yield }\end{array}$ & $\begin{array}{c}1 \text { y Treasury } \\
\text { yield }\end{array}$ & $\begin{array}{c}5 \text { y Treasury } \\
\text { yield }\end{array}$ & $\begin{array}{c}10 \text { y Treasury } \\
\text { yield }\end{array}$ \\
\hline \multicolumn{9}{|l|}{ 1. Intercept term } \\
\hline Regime 1 & $-0.348^{* * *}$ & $0.064^{* *}$ & $1.161^{* * *}$ & $-1.063^{* * *}$ & $-0.150 * * *$ & 0.076 & $0.236^{*}$ & 0.261 \\
\hline (Low rates/High spreads) & $(0.000)$ & $(0.049)$ & $(0.008)$ & $(0.000)$ & $(0.005)$ & $(0.489)$ & $(0.069)$ & $(0.229)$ \\
\hline Regime 2 & -0.237 & $0.127 * *$ & $2.222^{* * *}$ & $-1.252^{* * *}$ & $-0.147^{* * *}$ & $0.098^{* *}$ & $0.310^{* * *}$ & $0.319 * *$ \\
\hline (High rates/Low spreads) & $(0.147)$ & $(0.013)$ & $(0.000)$ & $(0.000)$ & $(0.006)$ & $(0.027)$ & $(0.002)$ & $(0.032)$ \\
\hline Regime 3 & -0.056 & $0.148^{* * *}$ & 0.748 & -1.156 & $-0.134^{* *}$ & 0.048 & 0.218 & 0.263 \\
\hline (Crisis) & $(0.689)$ & $(0.010)$ & $(0.986)$ & $(0.854)$ & $(0.020)$ & $(0.564)$ & $(0.187)$ & $(0.328)$ \\
\hline \multicolumn{9}{|l|}{ 2. VAR(1) Matrix } \\
\hline Investment Grade ST & $0.720 * * *$ & $0.010 * *$ & 0.921 & $0.076^{* *}$ & $-0.116^{* * *}$ & -0.009 & 0.047 & 0.042 \\
\hline$(\mathrm{t}-1)$ & $(0.000)$ & $(0.016)$ & $(0.125)$ & $(0.04)$ & $(0.000)$ & $(0.729)$ & $(0.763)$ & $(0.631)$ \\
\hline Investment Grade LT & $0.215^{* * *}$ & $0.945^{* * *}$ & 0.026 & 0.164 & $0.093^{* * *}$ & -0.004 & $-0.089 * *$ & $-0.084 * * *$ \\
\hline$(\mathrm{t}-1)$ & $(0.000)$ & $(0.000)$ & $(0.716)$ & $(0.352)$ & $(0.003)$ & $(0.545)$ & $(0.047)$ & $(0.002)$ \\
\hline Non-Investment Grade ST & $0.004^{* * *}$ & 0.001 & $0.706^{* * *}$ & $0.112^{* * *}$ & 0.001 & $-0.001^{* *}$ & $0.002^{*}$ & $0.001^{* * *}$ \\
\hline$(\mathrm{t}-1)$ & $(0.004)$ & $(0.173)$ & $(0.000)$ & $(0.000)$ & $(0.767)$ & $(0.015)$ & $(0.001)$ & $(0.000)$ \\
\hline Non-Investment Grade LT & -0.001 & -0.003 & $0.179 * * *$ & $0.690 * * *$ & 0.006 & -0.002 & -0.004 & $-0.001 *$ \\
\hline$(t-1)$ & $(0.110)$ & $(0.815)$ & $(0.005)$ & $(0.000)$ & $(0.310)$ & $(0.483)$ & $(0.108)$ & $(0.100)$ \\
\hline 1 m Treasury yield & -0.061 & 0.024 & -0.014 & $0.041^{* *}$ & $0.859 * * *$ & $-0.038^{* * *}$ & -0.006 & 0.011 \\
\hline$(\mathrm{t}-1)$ & $(0.202)$ & $(0.236)$ & $(0.169)$ & $(0.045)$ & $(0.000)$ & $(0.000)$ & $(0.141)$ & $(0.726)$ \\
\hline 1 y Treasury yield & 0.056 & -0.024 & -0.596 & $0.188^{*}$ & $0.154^{* * *}$ & $1.029 * * *$ & 0.018 & -0.016 \\
\hline$(\mathrm{t}-1)$ & $(0.483)$ & $(0.528)$ & $(0.846)$ & $(0.074)$ & $(0.000)$ & $(0.000)$ & $(0.252)$ & $(0.813)$ \\
\hline 5 y Treasury yield & -0.009 & $-0.054^{* *}$ & 2.200 & -1.399 & -0.002 & 0.027 & $0.962^{* * *}$ & 0.026 \\
\hline$(\mathrm{t}-1)$ & $(0.954)$ & $(0.023)$ & $(0.288)$ & $(0.379)$ & $(0.108)$ & $(0.232)$ & $(0.000)$ & $(0.112)$ \\
\hline 10 y Treasury yield & 0.069 & $0.051 *$ & -1.756 & $1.405^{*}$ & 0.007 & -0.030 & -0.012 & $0.936^{* * *}$ \\
\hline$(\mathrm{t}-1)$ & $(0.577)$ & $(0.005)$ & $(0.164)$ & $(0.068)$ & $(0.761)$ & $(0.648)$ & $(0.548)$ & $(0.000)$ \\
\hline$R$-squared & 0.931 & 0.982 & 0.942 & 0.909 & 0.995 & 0.995 & 0.999 & 0.990 \\
\hline \multicolumn{9}{|l|}{ 3.Unconditional mean } \\
\hline Regime 1 (Low rates/High spreads) & 8.672 & 13.499 & 31.833 & 34.700 & -40.150 & -38.493 & -25.442 & -15.112 \\
\hline Regime 2 (High rates/Low spreads) & -0.401 & -0.606 & 0.311 & -1.864 & 11.028 & 10.978 & 8.694 & 7.277 \\
\hline Regime 3 (Crisis) & 3.818 & 4.958 & 23.710 & 15.475 & -6.803 & -6.100 & -1.657 & 0.993 \\
\hline
\end{tabular}


Table 7 (Continued)

\begin{tabular}{|c|c|c|c|c|c|c|c|c|}
\hline & $\begin{array}{l}\text { Investment } \\
\text { Grade ST }\end{array}$ & $\begin{array}{c}\text { Investment } \\
\text { Grade LT }\end{array}$ & $\begin{array}{c}\text { Non-Investment } \\
\text { Grade ST }\end{array}$ & $\begin{array}{l}\text { Non-Investment } \\
\text { Grade LT }\end{array}$ & $\begin{array}{c}1 \mathrm{~m} \text { Treasury } \\
\text { yield }\end{array}$ & $\begin{array}{l}1 \text { y Treasury } \\
\text { yield }\end{array}$ & $\begin{array}{l}5 \text { y Treasury } \\
\text { yield }\end{array}$ & $\begin{array}{c}10 \text { y Treasury } \\
\text { yield }\end{array}$ \\
\hline $\begin{array}{l}\text { 4. Correlations/Volatilities } \\
\text { Regime } 1\end{array}$ & & & & & & & & \\
\hline Investment Grade ST & 0.809 & & & & & & & \\
\hline Investment Grade LT & 0.738 & 0.251 & & & & & & \\
\hline Non-Investment Grade ST & 0.736 & 0.784 & 2.150 & & & & & \\
\hline Non-Investment Grade LT & 0.768 & 0.785 & 0.915 & 1.332 & & & & \\
\hline $1 \mathrm{~m}$ Treasury yield & -0.182 & -0.161 & -0.113 & -0.108 & 0.311 & & & \\
\hline 1 y Treasury yield & -0.170 & -0.147 & -0.088 & -0.069 & 0.580 & 0.155 & & \\
\hline 5 y Treasury yield & -0.133 & -0.083 & 0.090 & 0.053 & 0.238 & 0.707 & 0.133 & \\
\hline $\begin{array}{c}10 \text { y Treasury yield } \\
\text { Regime } 2\end{array}$ & -0.088 & -0.008 & 0.181 & 0.119 & 0.145 & 0.539 & 0.941 & 0.102 \\
\hline Investment Grade ST & 0.071 & & & & & & & \\
\hline Investment Grade LT & 0.315 & 0.070 & & & & & & \\
\hline Non-Investment Grade ST & 0.077 & 0.170 & 0.908 & & & & & \\
\hline $1 \mathrm{~m}$ Treasury yield & -0.007 & 0.051 & -0.065 & 0.040 & 0.058 & & & \\
\hline 1 y Treasury yield & 0.080 & -0.085 & 0.030 & -0.096 & 0.173 & 0.033 & & \\
\hline 5 y Treasury yield & 0.082 & -0.060 & 0.066 & -0.116 & 0.079 & 0.703 & 0.075 & \\
\hline $\begin{array}{c}10 \text { y Treasury yield } \\
\text { Regime } 3\end{array}$ & 0.076 & -0.024 & 0.119 & -0.098 & 0.042 & 0.592 & 0.918 & 0.077 \\
\hline Investment Grade ST & 0.370 & & & & & & & \\
\hline Investment Grade LT & 0.818 & 0.285 & & & & & & \\
\hline Non-Investment Grade ST & 0.486 & 0.423 & 3.736 & & & & & \\
\hline Non-Investment Grade LT & 0.081 & 0.036 & 0.320 & 2.609 & & & & \\
\hline $1 \mathrm{~m}$ Treasury yield & -0.174 & -0.046 & -0.055 & 0.112 & 0.048 & & & \\
\hline 1 y Treasury yield & 0.142 & 0.244 & -0.045 & -0.224 & 0.360 & 0.059 & & \\
\hline 5 y Treasury yield & -0.025 & -0.040 & -0.134 & -0.331 & 0.003 & 0.526 & 0.153 & \\
\hline 10 y Treasury yield & -0.041 & -0.082 & -0.028 & -0.270 & 0.014 & 0.391 & 0.892 & 0.173 \\
\hline 5.Transition Matrix & \multicolumn{2}{|c|}{ Regime 1} & \multicolumn{2}{|c|}{ Regime 2} & \multicolumn{2}{|c|}{ Regime 3} & & \\
\hline Regime 3 (Crisis) & \multicolumn{2}{|c|}{0.034} & \multicolumn{2}{|c|}{0.112} & \multicolumn{2}{|c|}{0.854} & & \\
\hline
\end{tabular}

${ }^{*}$ significat at $10 \%$ level, ${ }^{* *}$ significant at $5 \%$ level, ${ }^{* * *}$ significant at $1 \%$ level 


\section{Figure 1: Corporate yields}

The figure plots corporate yield series from October 8, 2004 to December 28, 2012 for four portfolios built on the basis of residual time to maturity and rating. The data are expressed in terms of annualized percentage nominal yields.

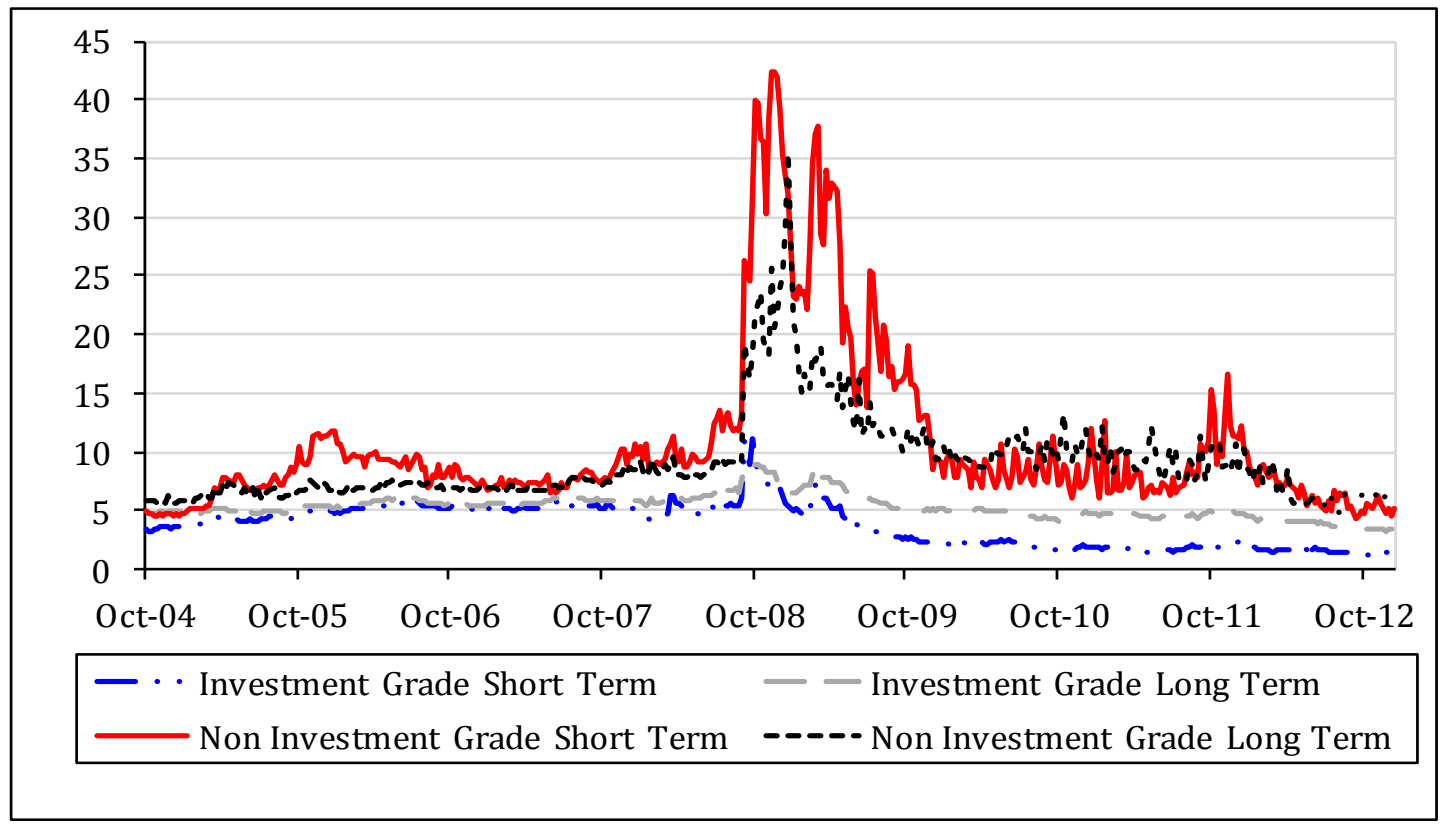

Figure 2: Treasury yields

The figure plots the Treasury 1-month, 1-, 5-, and 10-year constant-maturity yields from October 8, 2004 to December 28, 2012. The data are expressed in terms of annualized percentage nominal yields.

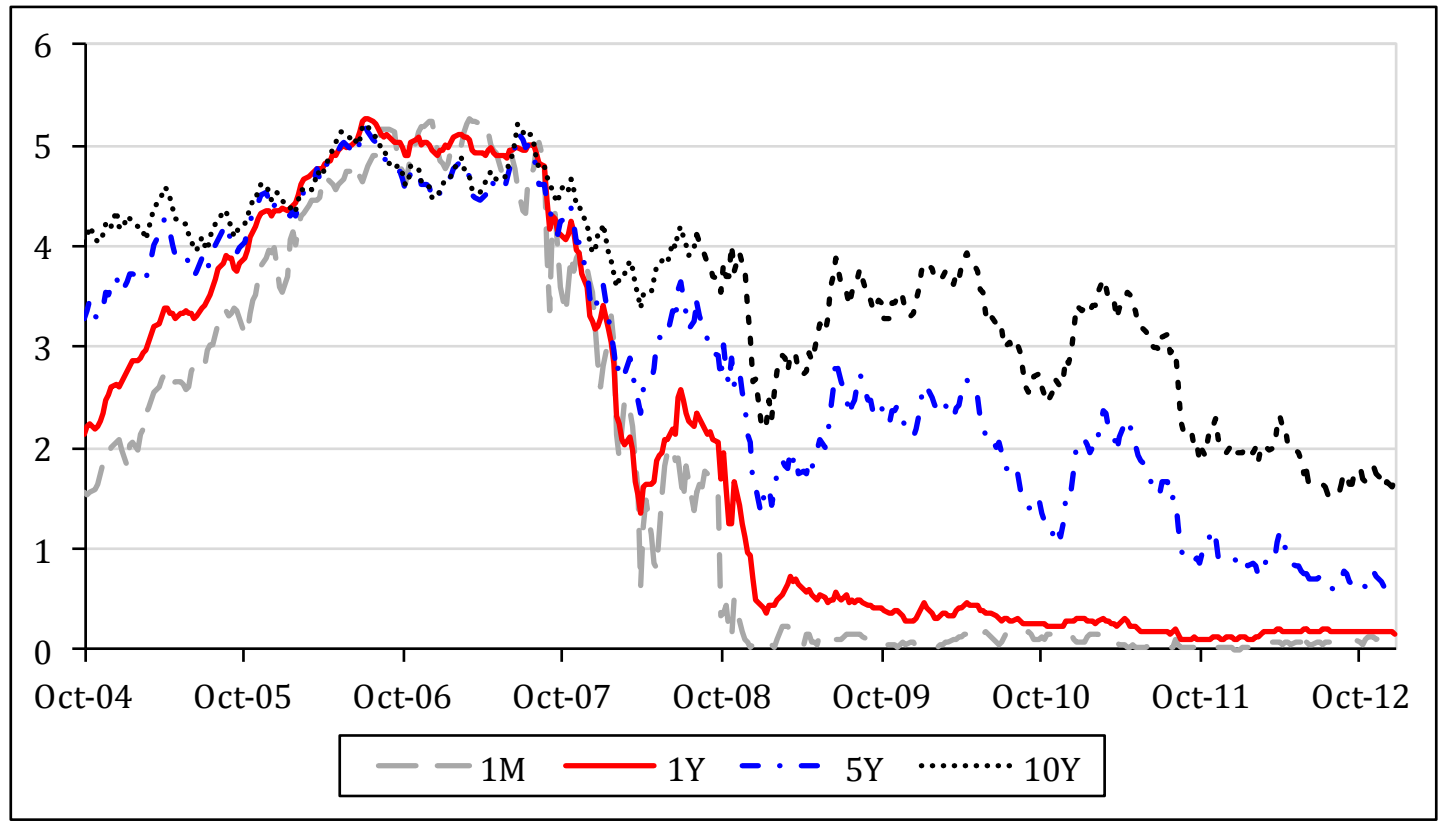




\section{Figure 3: Principal components factor loadings}

The figure shows the factor loadings of the three components - level, slope and curvature - that are used to decompose the Treasury term structure.

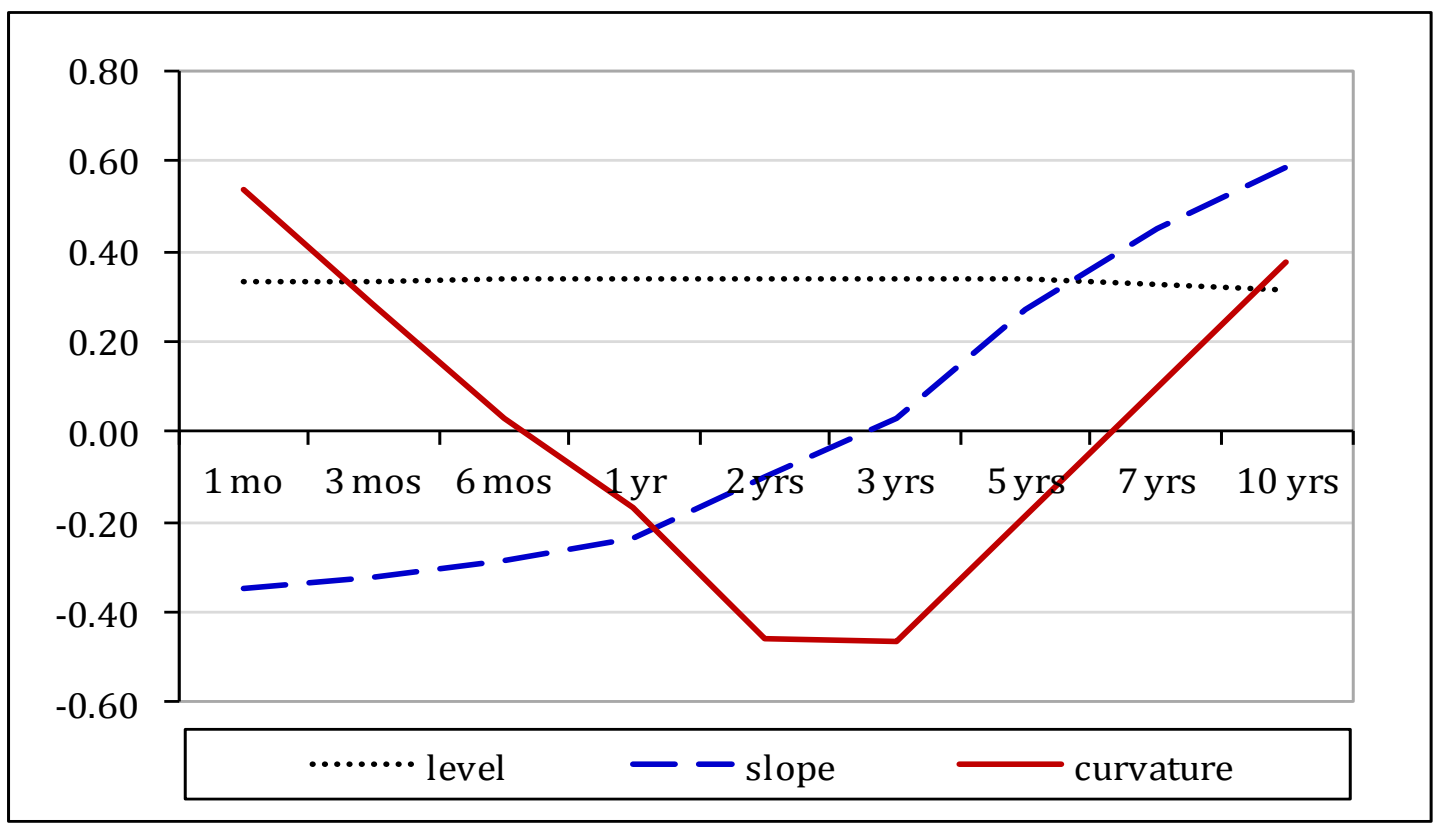


Figure 4: VAR-yields: Impulse responses to quantitative easing
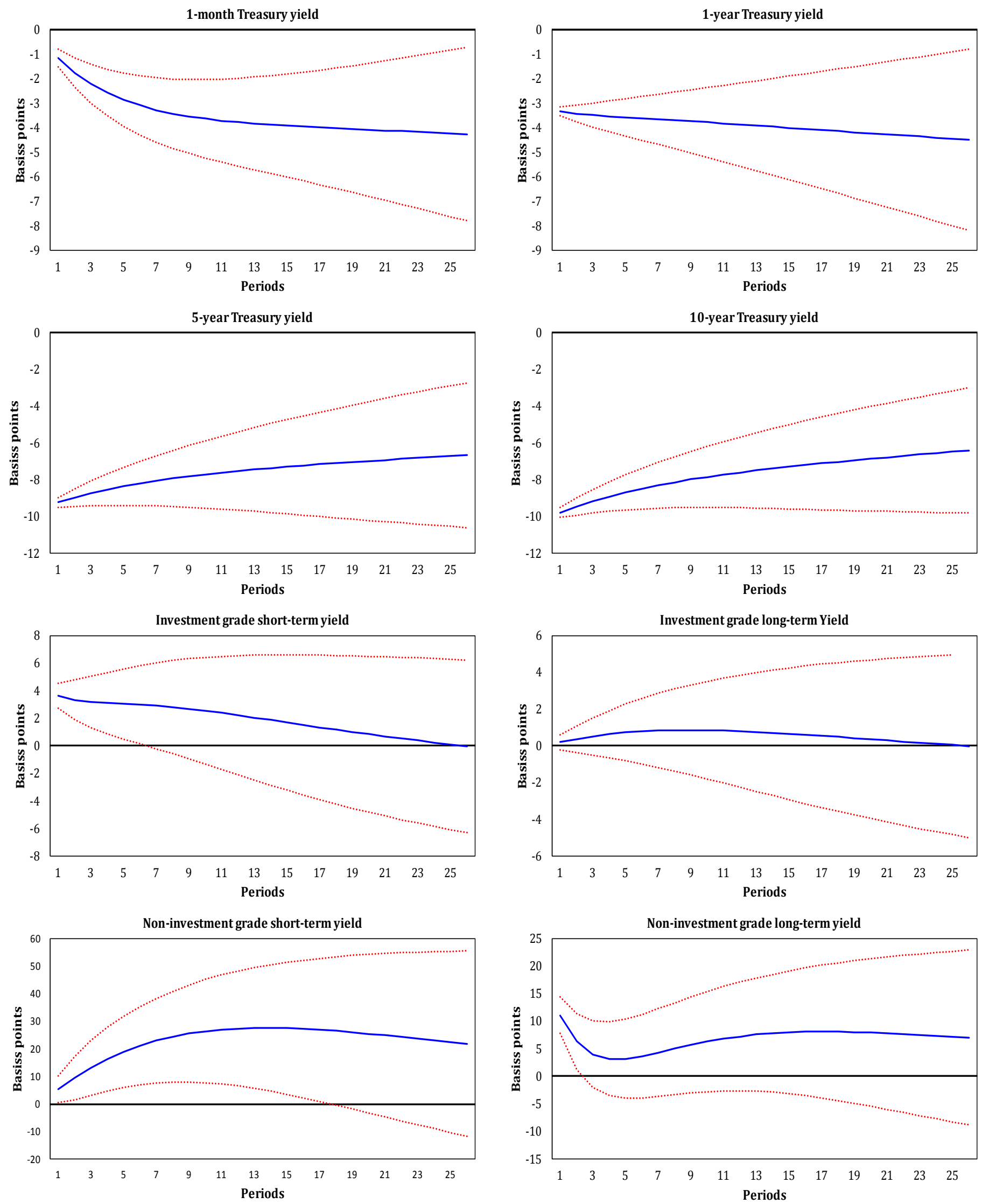


\section{Figure 5: VAR-yields: Impulse responses to operation twist}
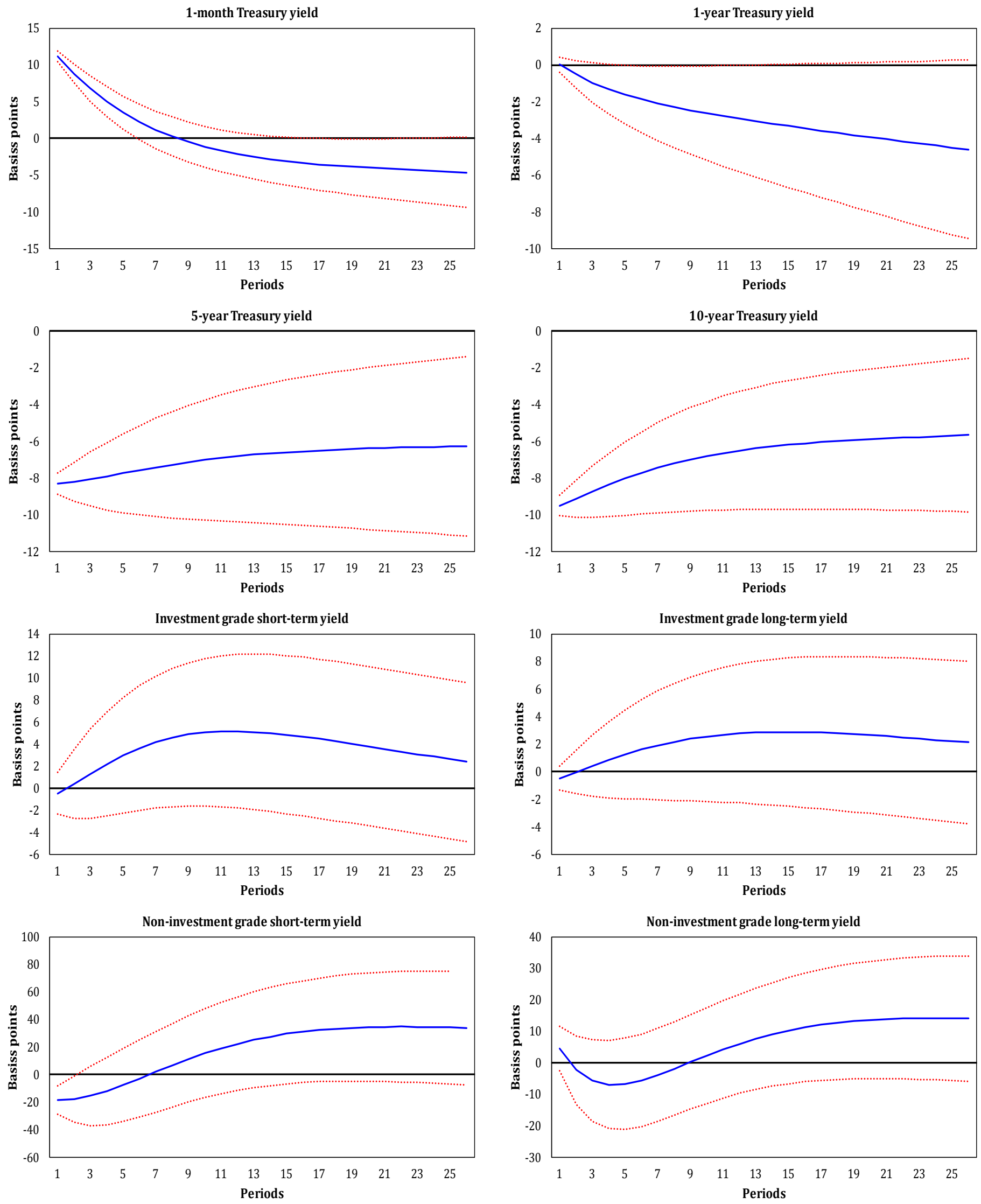
Figure 6: MSVAR-yields: Smoothed probabilities

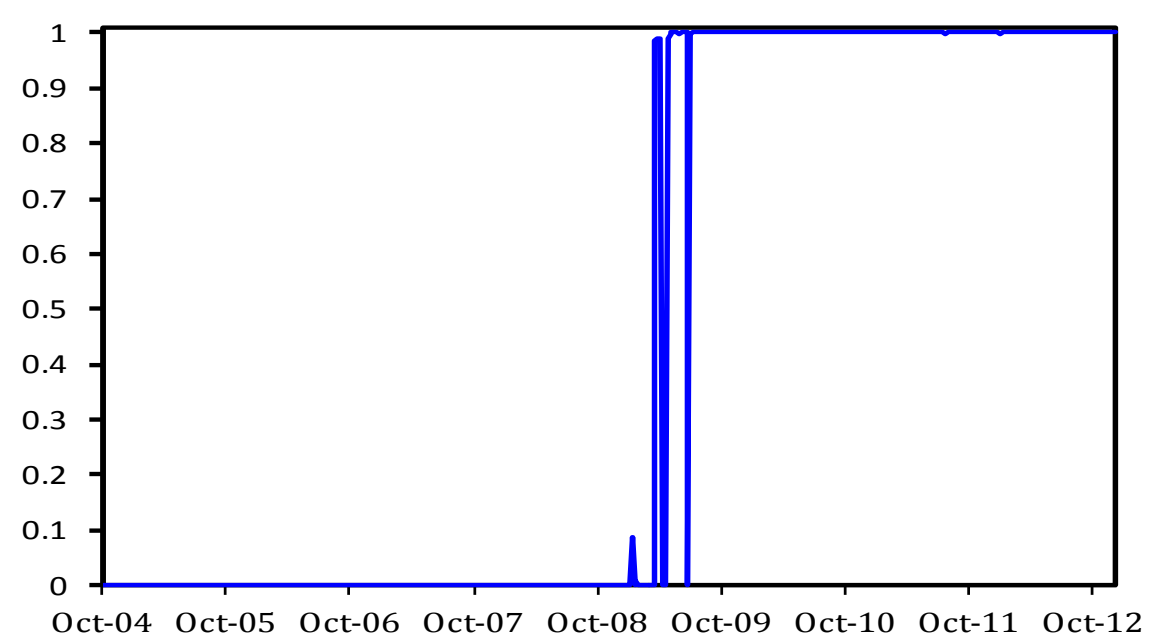

—Low yields/High Spreads

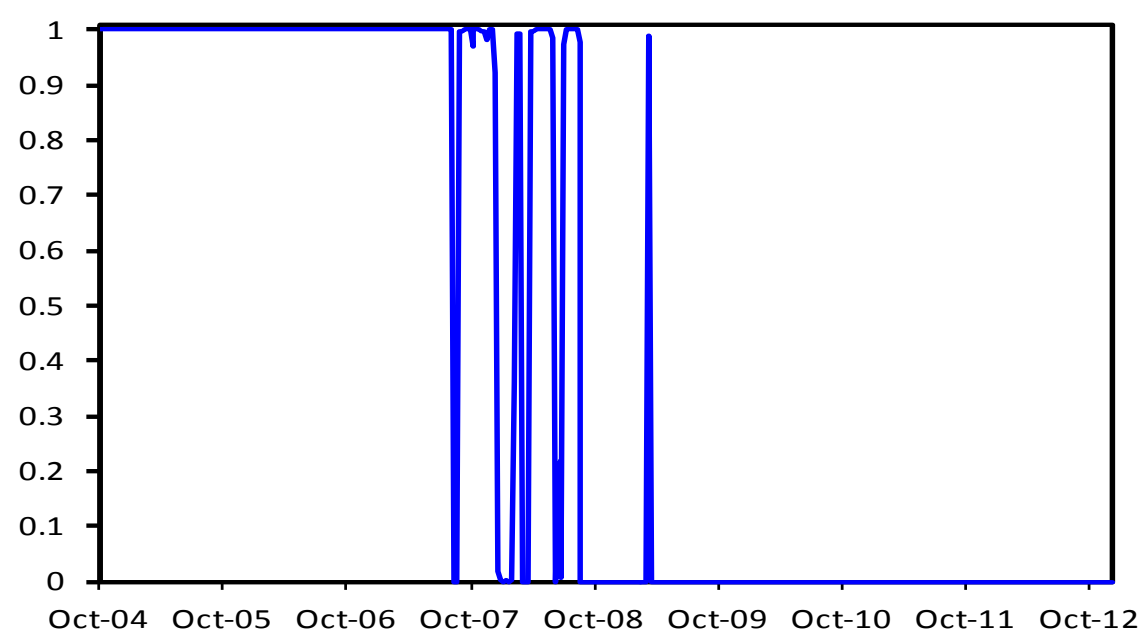

— High yield/Low Spreads

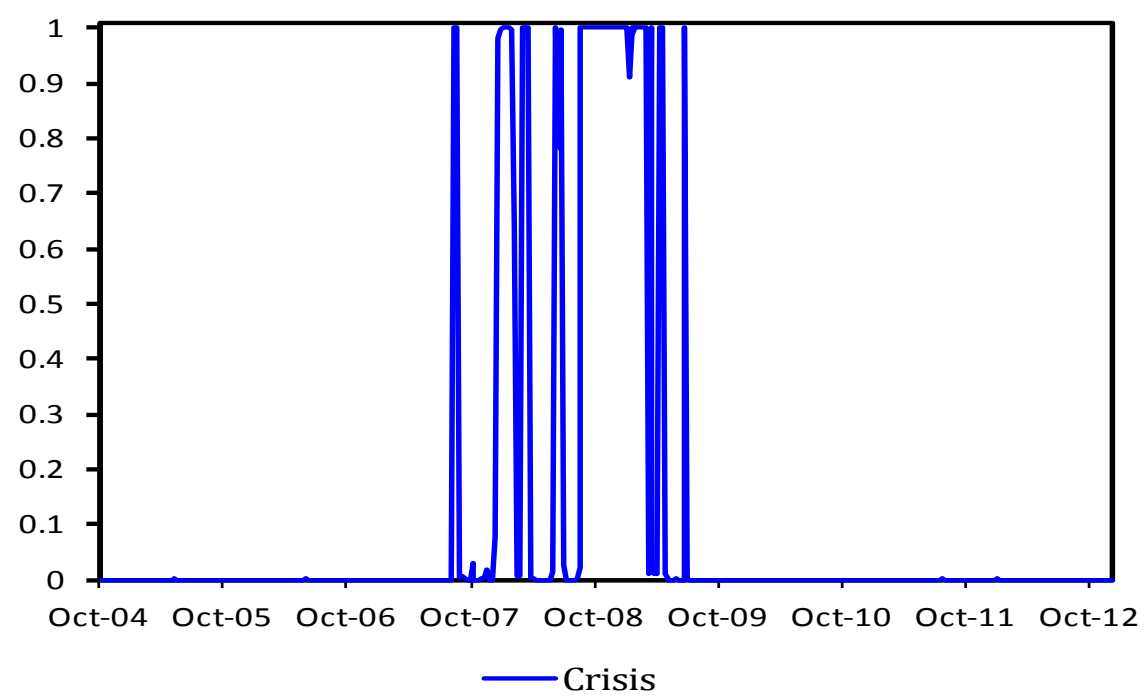


Figure 7: MSVAR-spreads: Smoothed probabilities

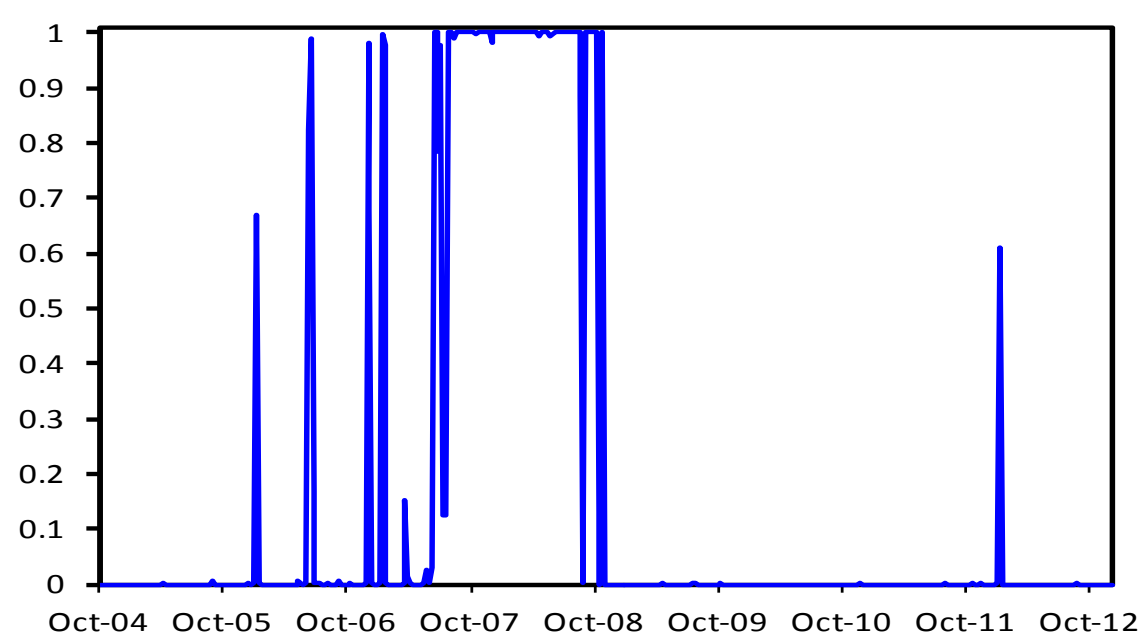

—Low yields/High Spreads

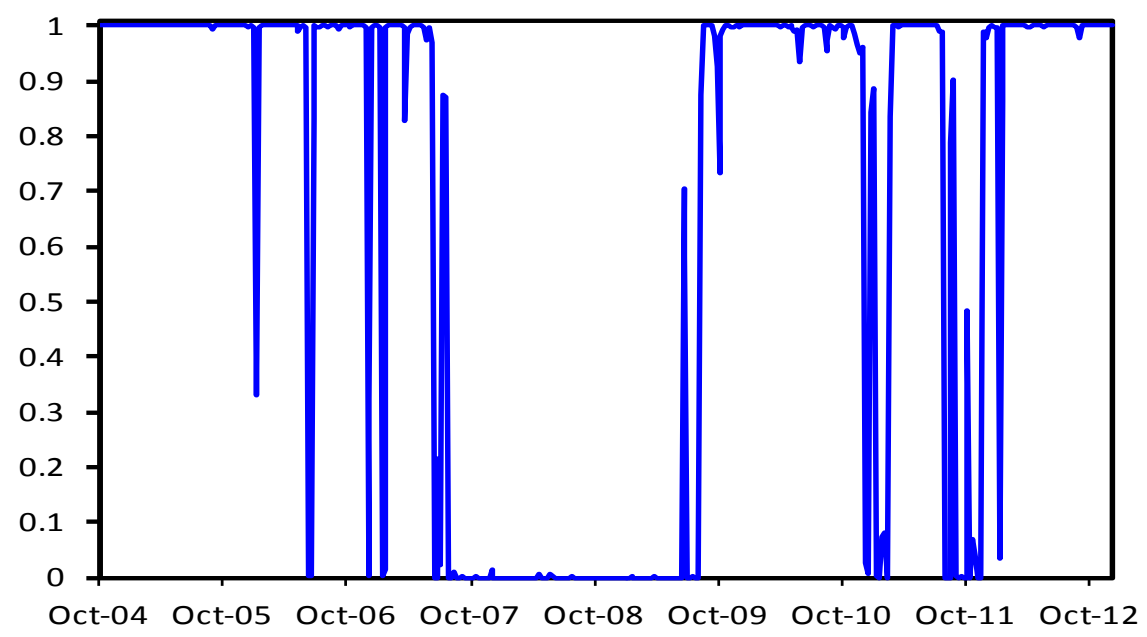

—High yields/Low Spreads

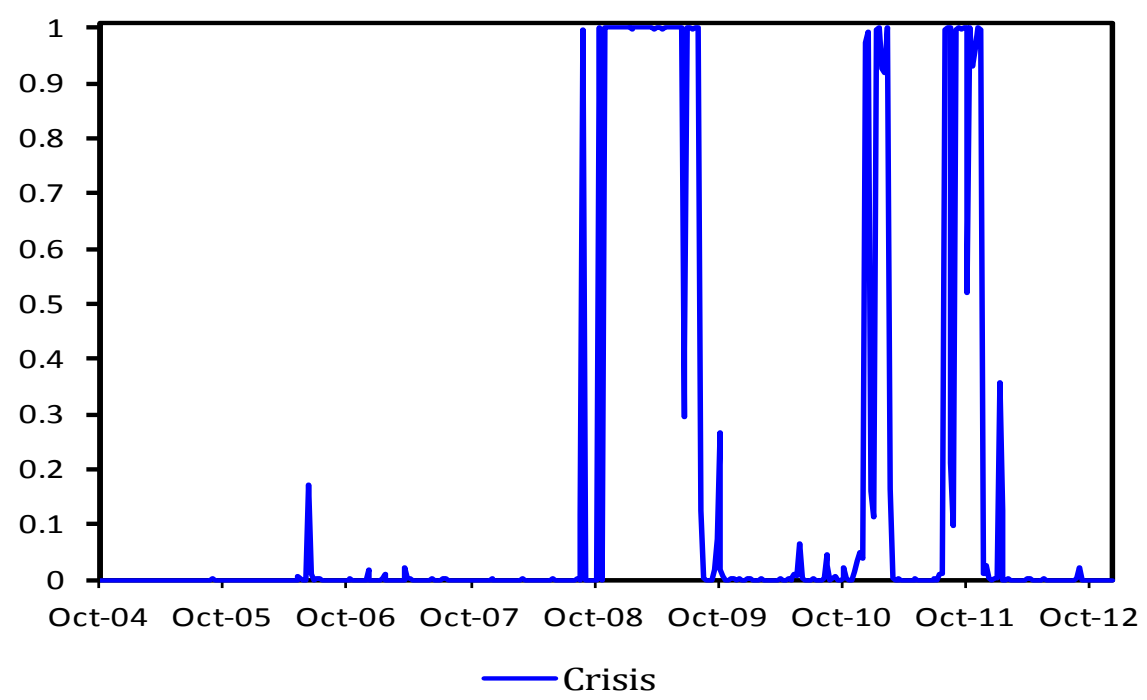




\section{Figure 8: MSVAR-yields: Impulse responses to conventional monetary policy}

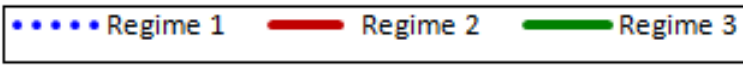
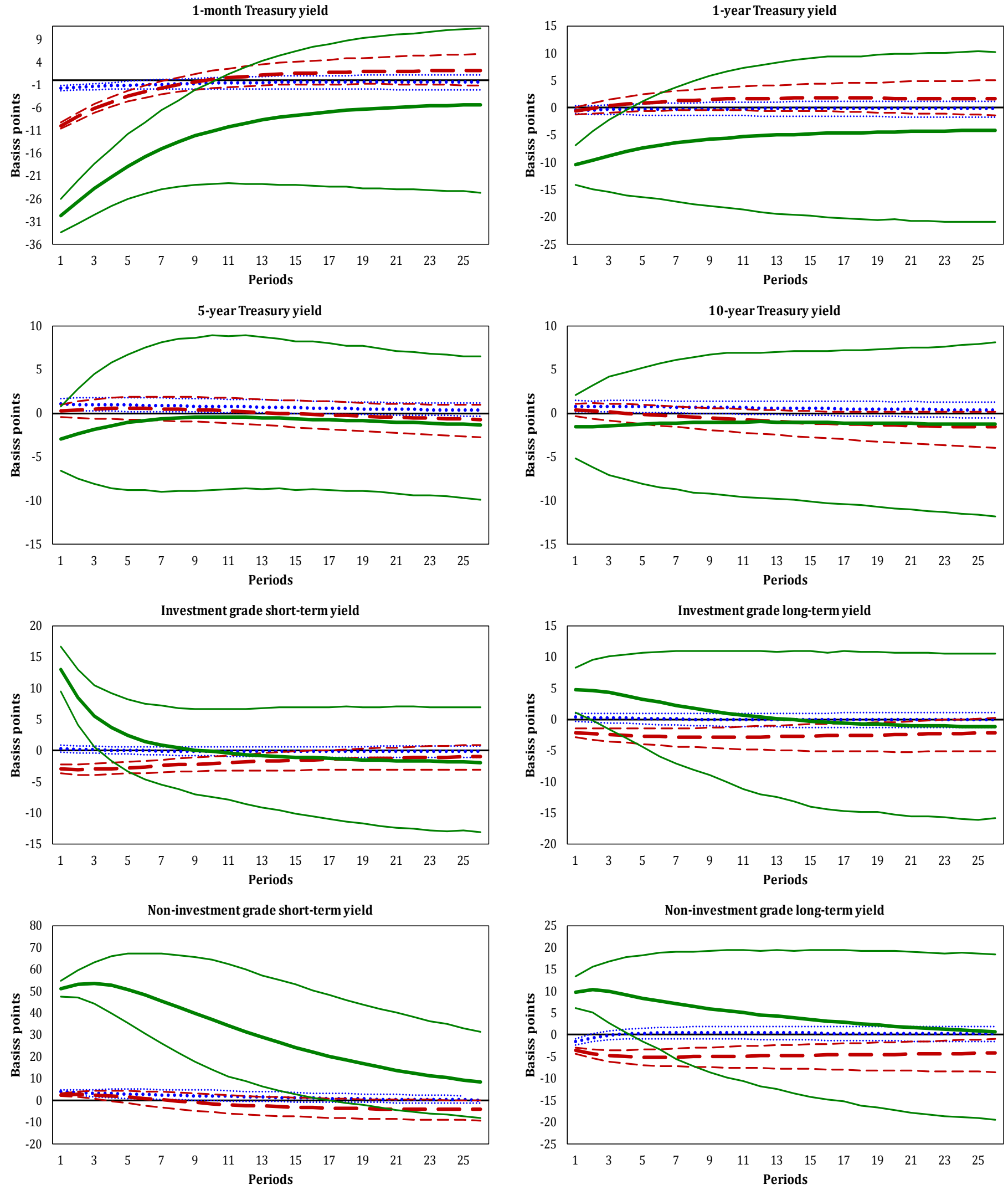


\section{Figure 9: MSVAR-yields: Impulse responses to quantitative easing}
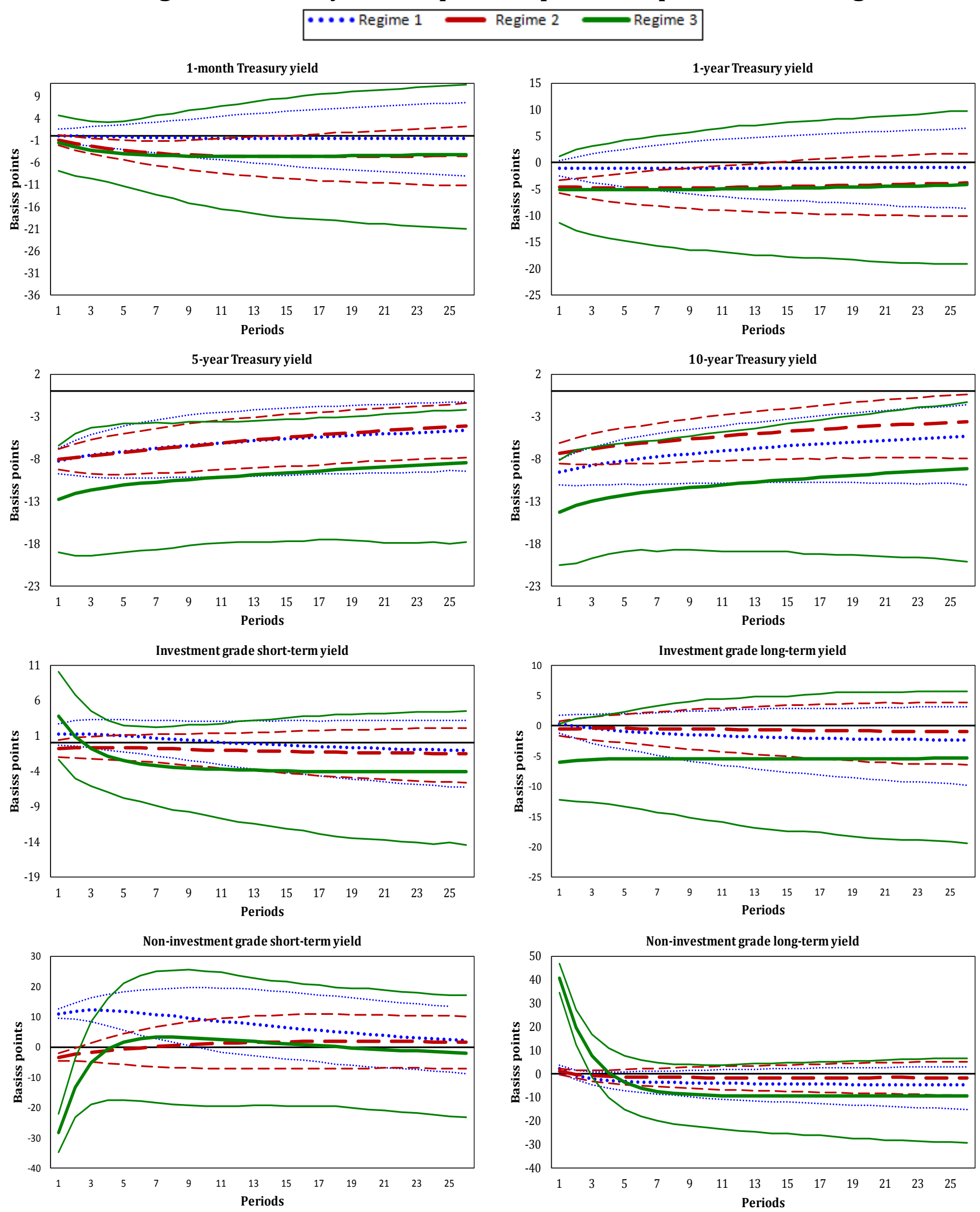


\section{Figure 10: MSVAR-yields: Impulse responses to operation twist}
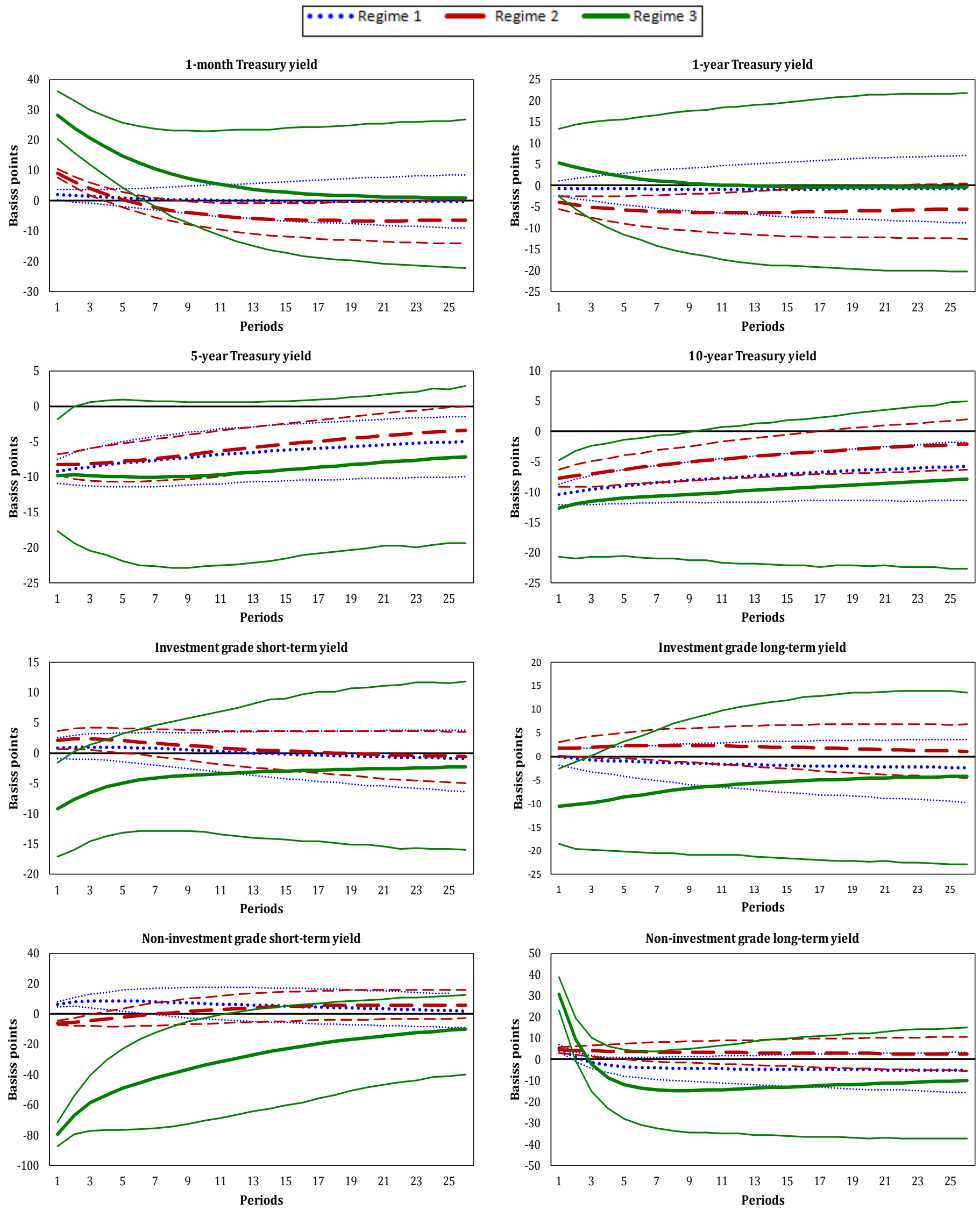


\section{Figure 11: MSVAR-spreads: Impulse responses to conventional monetary policy}
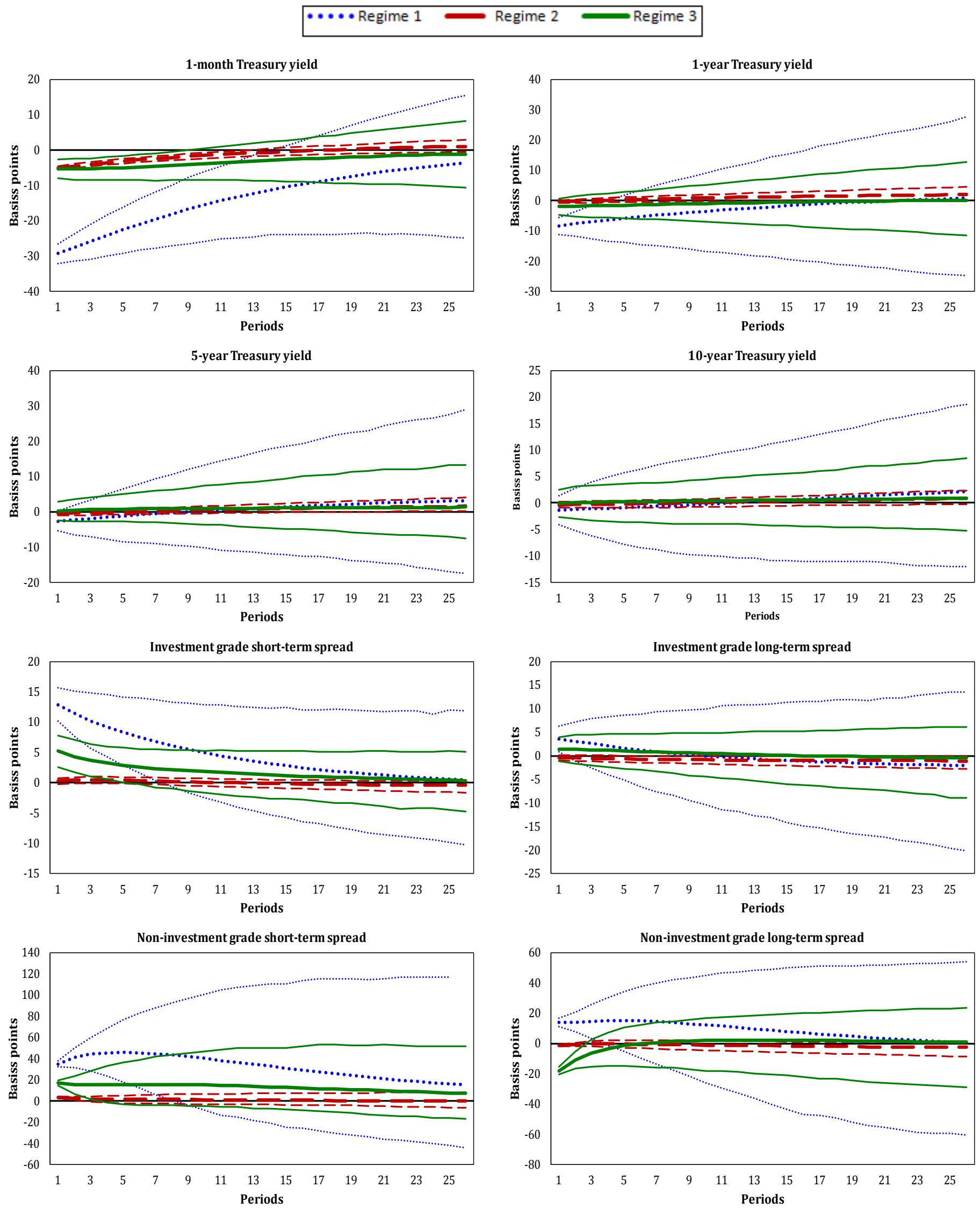


\section{Figure 12: MSVAR-spreads: Impulse responses to quantitative easing}

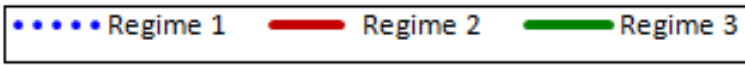
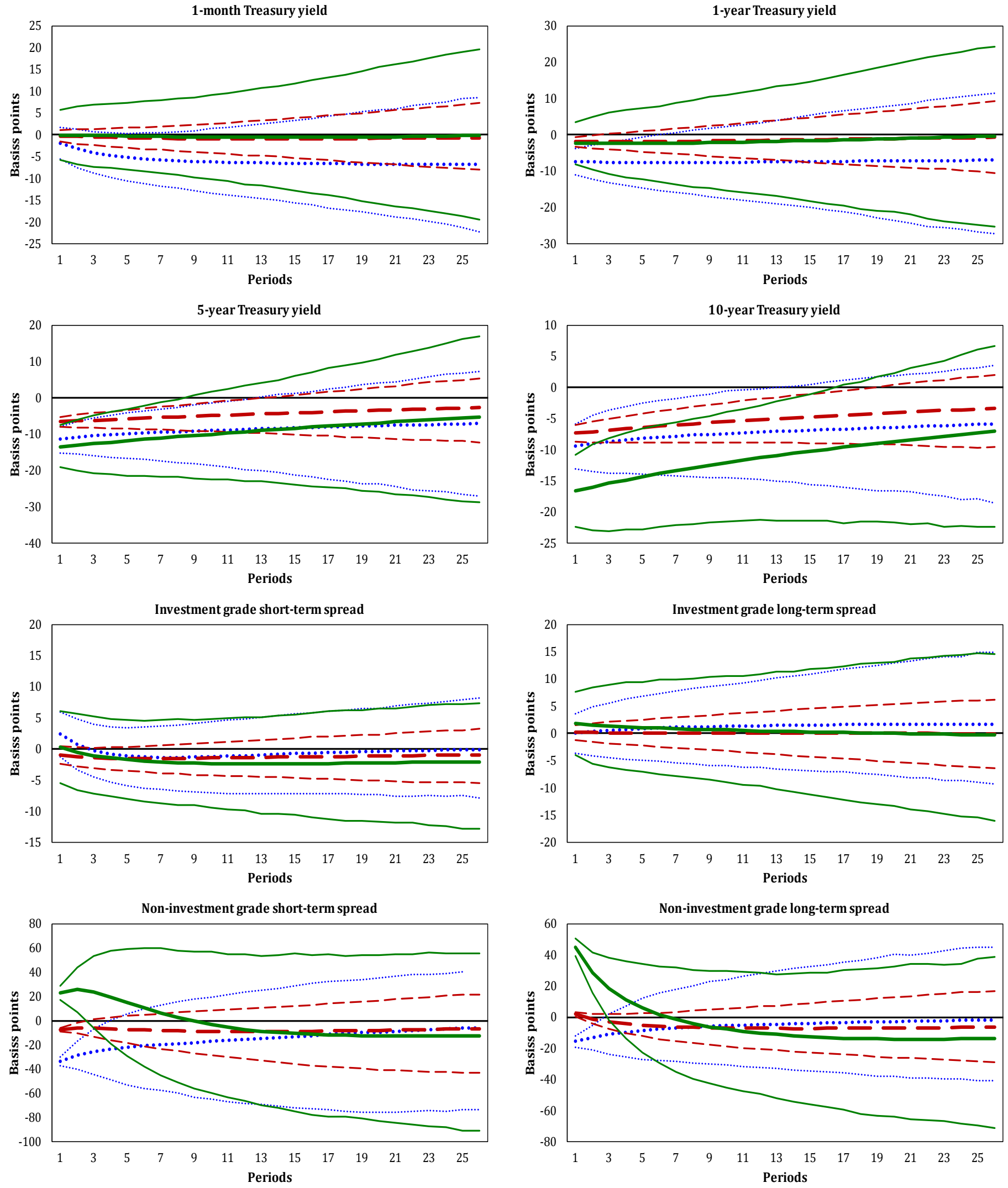


\section{Figure 13: MSVAR-spreads: Impulse responses to operation twist}
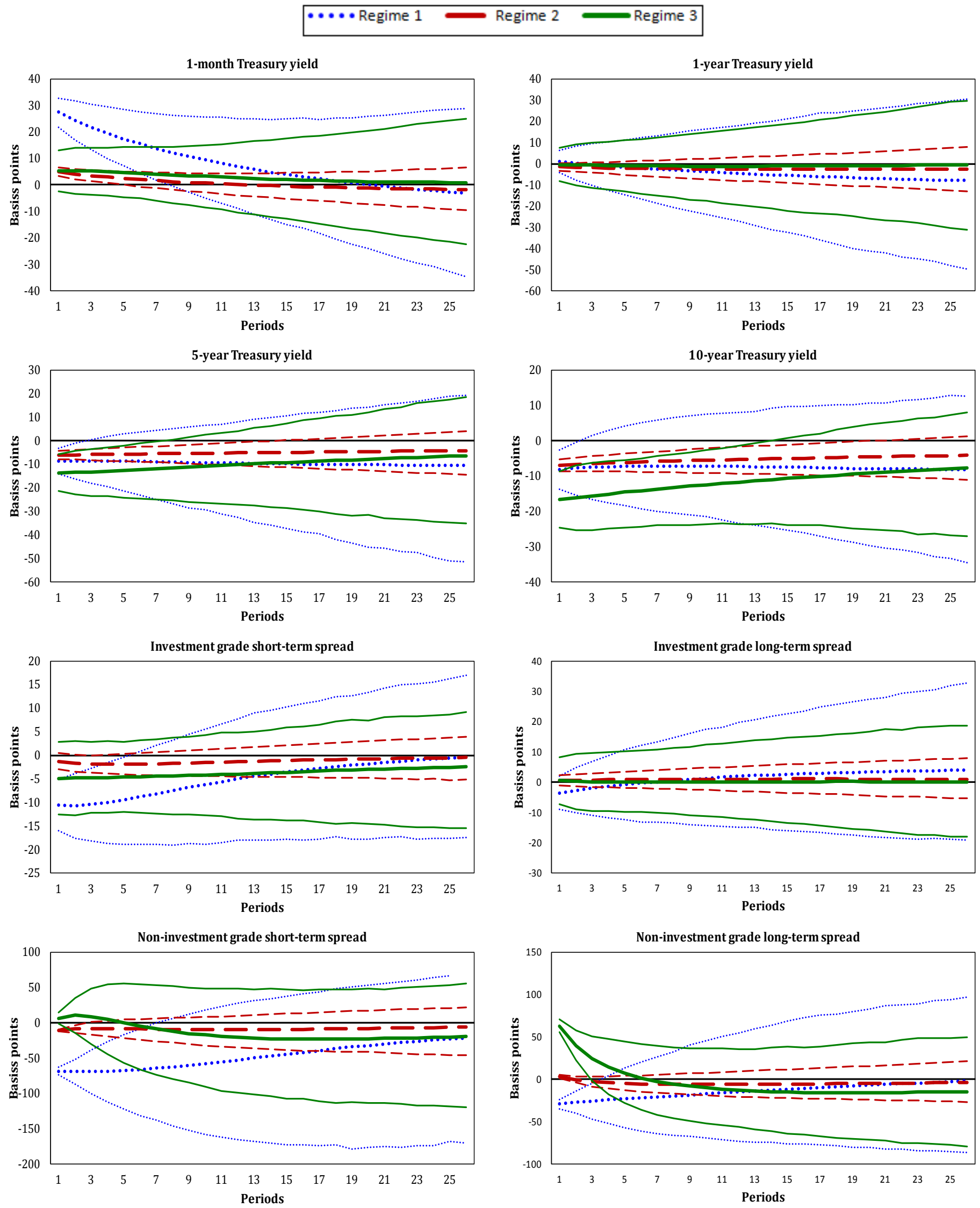